3 Research s gure

\title{
Assessment of Spatio-temporal Variations of Selected Water Quality Parameters of Lake Ziway, Ethiopia Using Multivariate Techniques
}

Dessie Tibebe ( $\sim$ dessie.1977@gmail.com )

University of Gondar

Feleke Zewge

Addis Ababa University

Brook Lemma

Addis Ababa University

Yezbie Kassa

University of Gondar

\section{Research Article}

Keywords: Cluster Analysis, Comprehensive pollution index, Factor Analysis, Principal Component Analysis

Posted Date: December 21st, 2021

DOI: https://doi.org/10.21203/rs.3.rs-1102595/v1

License: (c) (1) This work is licensed under a Creative Commons Attribution 4.0 International License. Read Full License

Version of Record: A version of this preprint was published at BMC Chemistry on March 14th, 2022. See the published version at https://doi.org/10.1186/s13065-022-00806-0. 


\section{Abstract}

Lake Ziway is shallow freshwater located in Northern part of Ethiopian Rift Valley. It is characterized as semi-arid to sub-humid type of climate. Expansions of the flower industry, widespread fisheries, intensive agricultural activities, fast population growth lead to deterioration of water quality and depletion of aquatic biota. In this study, spatial and temporal variations of selected water quality parameters of Lake Ziway were evaluated using multivariate statistical techniques in the study periods of 2014 and 2015. Monthly water quality data were collected from nine sampling stations during dry and wet seasonal basis for analysis of 15 water quality parameters. Mean nutrient concentrations showed increasing trend and were higher in Floriculture effluent $(\mathrm{Fb})$ and Floriculture effluent after mixing in the lake ( $\mathrm{Fa})$ in all seasons. These sites were also characterized by high electrical conductivity (EC) and total dissolved solid (TDS). All the nine sampling sites were categorized into three pollution levels according to their water quality features using cluster analysis (CA). Accordingly, sampling sites Fb and Ketar River (Kb) are highly and moderately polluted in both seasons, respectively. On the other hand, sampling sites at the center (C), Meki river mouth (Ma), Ketar river mouth $(\mathrm{Ka})$, Meki River $(\mathrm{Mb})$, Korekonch $\left(\mathrm{K}_{\mathrm{o}}\right)$ and $\mathrm{Fa}$ in dry season and $\mathrm{Ka}, \mathrm{C}, \mathrm{Ma}, \mathrm{Ko}$, Bulbula river mouth $(\mathrm{B})$ and Fa during wet season were less polluted. Principal component analysis (PCA) analysis also showed the pollutant sources were mainly from Fb during dry season $\mathrm{Mb}$ and $\mathrm{Kb}$ during wet season. The values of comprehensive pollution index illustrated the lake is moderately and slightly polluted in dry and wet seasons, respectively. Comparatively, the pollution status of the lake is high around floriculture effluent discharge site and at the two feeding rivers ( $\mathrm{Kb}$ and $\mathrm{Mb}$ ) due to increasing trends in agrochemical loads. This may lead to long term ecological changes in the lake unless possible measures taken.

\section{Introduction}

A lake's water quality is a reflection of what happens in its watershed as watershed topography, soil, geology, vegetation and anthropogenic pressures determine the kinds of materials entering into it. Nutrient enrichment of lakes is considered to be one of the major environmental problems in many countries especially in developing ones (Razmkhah, et al., 2010). In recent decades, population growth, agricultural practices and sewage runoff from urban areas have increased nutrient inputs many folds to the level of their natural occurrence, resulting in accelerated eutrophication (Varol et al., 2009; Razmkhah, et al., 2010). Many urban and rural lakes have vanished under this pressure with worldwide environmental concerns (Badillo-Camacho et al., 2015).

Lake Ziway is shallow freshwater located in the most northern section of the Ethiopian Rift Valley. The region is characterized as semi-arid to sub-humid type of climate and has mean annual precipitation varying between $650 \mathrm{~mm}$ and $1200 \mathrm{~mm}$ and mean annual temperature between 15 and $25^{\circ} \mathrm{C}$ (Legesse et al., 2001; Mesfin and Beyene, 2012). During the last few decades, Lake Ziway has begun to show reduction in its water level because of some climatic factors and excessive water abstraction for irrigation, municipals and industrial purposes (Ayenew and Legesse, 2007). The lake is fed primarily by Meki and Ketar Rivers and drained by the Bulbula River. The lake's catchment has an area of $7025 \mathrm{~km}^{2}$ with the town of Ziway lying on the lake's western shore (Ayenew and Legesse, 2007).

The population in the area around Lake Ziway has grown from twenty thousand fifty six to about forty three thousand six hundred sixty in during the last 20 years (Population and Housing Census of Ethiopia, 1994, 2007). The fishery of the lake is also an important source of livelihood to scores of fishermen and their families and provides the main source of food to many families within the lake basin and beyond. Tourism is also a major activity in the area: the lake ecosystem falls within one of the key tourist destinations in the country, such as scenery admiring and relaxing, island visiting and bird watching, Boating, canoeing and sport fishing, monastery visiting other socio-economic activities conducted along the lake's shore include livestock production and small-scale farming (Woldemanual, 2010; APHRD, 2010; Jansen et al., 2011).

Increase in agricultural activities like rapid expansion of the flower industry, widespread fisheries, irrigated agriculture (commercial farming) and fast population growth, industrialization and intensive use of agrochemicals are leading to the deterioration of lake water quality and depletion of aquatic biota. This has resulted in major changes in biological structures and dynamics of the lake and other freshwater, often showing significant shift from clear water to turbid state (Zeray et al., 2007; Ayenew and Legesse, 2007; Jansen et al., 2011). As a consequence, water pollution is currently a major environmental challenge at Lake Ziway. There have been few studies on various aspects of the biology of Lake Ziway in the past (Yohannes, 2003; Beneberu and Mengistou, 2009; Tilahun, 2006, 2010; Ayenew et al., 2007, 2008; Tadele, 2012; Tamire and Mengistu, 2012). Jansen et al. (2007) 
recommended that the detail water quality assessment of Lake Ziway should be conducted. However, studies on the comprehensive spatio-temporal variations and the systematic identification of the potential pollution sources of Lake Ziway water qualities were very limited. Thus, reliable information on water quality and pollution sources is important for effective lake water management.

Multivariate statistical techniques have been widely adopted to analyze and evaluate surface and freshwater water quality, and are useful to verify temporal and spatial variations caused by natural and anthropogenic factors linked to seasonality (Simeonov et al., 2010; Badillo-Camacho et al., 2015). Although the numerous management challenges, the multivariate techniques have a limited usage in the assessment of water quality in many lakes in developing countries including Lake Ziway. The aim of this study is to analyze the 15 water quality parameters from nine representative sampling sites of Lake Ziway, Ethiopia. The obtained data set is subjected to multivariate statistical methods to categories the lake on the basis of pollution levels/status and to identify the sources of pollution.

\section{Materials And Methods}

\section{Description of the study area}

The description of Lake Ziway has been provided in several publications (Turdu et al., 1999; Legesse et al., 2001, Zeray, et al., 2007). Therefore, only a brief description will be provided here. The Lake is situated at 1636 meters above sea level and at $08^{\circ} 01^{\prime} \mathrm{N}$ and $38^{\circ} 47^{\prime} \mathrm{E}$ (Figure 1) in a complex geological arrangement of sedimentary deposits.

Table 1

Geographic coordinates of the sample points

\begin{tabular}{|lllll|}
\hline Sampling Site Description & Abr. & North & East & Elevation (m) \\
\hline Floriculture effluent & $\mathrm{Fb}$ & $07^{0} 54.715^{\prime}$ & $038^{0} 44.020^{\prime}$ & 1642 \\
\hline Floriculture after mixing & $\mathrm{Fa}$ & $07^{0} 54.79^{\prime}$ & $038^{0} 144.111^{\prime}$ & 1639 \\
\hline Bulbula River mouth & $\mathrm{B}$ & $07^{0} 53.943^{\prime}$ & $038^{0} 44.134^{\prime}$ & 1641 \\
\hline Ketar River mouth & $\mathrm{Ka}$ & $07^{0} 55.398^{\prime}$ & $038^{0} 52.086^{\prime}$ & 1640 \\
\hline Ketar River at Abura Town & $\mathrm{Kb}$ & $08^{0} 02.019^{\prime}$ & $038^{0} 49.340^{\prime}$ & 1646 \\
\hline Meki River at Meki Town & $\mathrm{Mb}$ & $08^{0} 03.019^{\prime}$ & $039^{0} 01.144^{\prime}$ & 1673 \\
\hline Meki River mouth & $\mathrm{Ma}$ & $08^{0} 03.379^{\prime}$ & $038^{0} 56.459^{\prime}$ & 1633 \\
\hline Korekonch & $\mathrm{Kt}$ & $07^{0} 55.494^{\prime}$ & $038^{0} 43.697^{\prime}$ & 1637 \\
\hline Central station & $\mathrm{C}$ & $07^{0} 55.49^{\prime}$ & $038^{0} 52.934$ & 1635 \\
\hline
\end{tabular}

\section{Sampling and chemical analysis In-situ measurements}

All field equipments were calibrated according to the manufacturer's specifications. Temperature, $\mathrm{pH}$, electrical conductivity, total dissolved solids, and dissolved oxygen (DO) were measured with a portable ion meter $\left(\mathrm{HACH}^{\mathrm{TM}}\right.$ model150 made in Spain. Secchi depth (SD) was measured with a standard Secchi disk of $20 \mathrm{~cm}$ diameter.

\section{Water sampling}

Water samples were collected with a Van Dorn bottle sampler from different depths of the entire water column with $1 \mathrm{~m}$ intervals and mixed in equal proportions to produces composite samples at monthly intervals from nine selected sampling sites of the lake 
and its tributaries in 2014 and 2015 during dry season (November to April) and wet season (May to October). The collected water samples were kept in $1 \mathrm{~L}$ polyethylene plastic bottles (Table 1). All water samples were stored in insulated cooler containing ice and taken on the same day to laboratory and stored at $4^{\circ} \mathrm{C}$ before analysis.

\section{Chemical analysis}

Concentrations of inorganic nutrients $\left(\mathrm{NO}_{2}-\mathrm{N}, \mathrm{NO}_{3}-\mathrm{N}, \mathrm{PO}_{4}-\mathrm{P}, \mathrm{NH}_{3}-\mathrm{N}\right.$, total phosphorus (TP), total nitrogen (TN), total inorganic nitrogen $(\mathrm{TIN})$ and soluble reactive silica $\left(\mathrm{SiO}_{2}-\mathrm{Si}\right)$ were determined for all samples following the standard procedures outlined in (APHA) et al. (1999). Table 2 summarizes the analytical methods for surface water samples.

Table 2

Summary of analytical methods used for surface water sample (APHA, 1999)

\begin{tabular}{|c|c|c|}
\hline Parameter & Method & Description \\
\hline Total alkalinity & APHA 2320 B & Titrimetric \\
\hline $\mathrm{pH}$ & Membrane Electrode & Portable $\mathrm{HACH}^{\mathrm{TM}}$ model 150 \\
\hline EC & Membrane Electrode & Portable $\mathrm{HACH}^{\mathrm{TM}}$ model 150 \\
\hline TDS & Membrane Electrode & Portable $\mathrm{HACH}^{\mathrm{TM}}$ model 150 \\
\hline Temperature & Membrane Electrode & Portable $\mathrm{HACH}^{\mathrm{TM}}$ model 150 \\
\hline Ammonia & APHA4500- $\mathrm{NH}_{3} \mathrm{C}$ & Spectrophotometric, Phenate \\
\hline Nitrate & Yang et al., 1998 & Spectrophotometric, sodium salicylate \\
\hline Nitrite & APHA4500- $\mathrm{NO}_{2}^{-} \mathrm{A}$ & Spectrophotometric, Colorimetric \\
\hline $\mathrm{TN}$ & APHA4500- N C & Spectrophotometric, Kjeldahl method \\
\hline Phosphate & APHA4500-P C & Spectrophotometric, Ascorbic Acid \\
\hline TP & APHA4500-P C & Spectrophotometric, Persulfate digestion method, then Ascorbic acid method \\
\hline Secchi depth & Lind & Field equipment \\
\hline Dissolved oxygen & Membrane Electrode & probe method (YSI model 58) \\
\hline Silica & APHA4500-SiO 2 & Spectrophotometric, Molybdosilicate Method \\
\hline
\end{tabular}

\section{Multivariate statistical methods}

Lake water quality data sets were subjected to three multivariate techniques: cluster analysis (CA), principal component analysis (PCA) and factor analysis (FA) (Zhao, 2012). All statistical analyses were performed using the SPSS statistical software (Version 20) and PAST statistical software (Version 1.93) (Zhao, 2012).

\section{Cluster analysis}

CA classifies objects, so that each object is similar to the others in the cluster with respect to a predetermined selection criterion. Hierarchical agglomerative clustering is the most common approach, which provides intuitive similarity relationships between any one sample and the entire data set and is typically illustrated by a dendrogram (tree diagram). The dendrogram provides a visual summary of the clustering processes, presenting a picture of the groups and their proximity with a dramatic reduction in dimensionality of the original data (Shrestha and Kazama, 2007; Sayadi et al., 2014; Badillo-Camacho et al., 2015). In this study, hierarchical agglomerative CA was carried out on the normalized data by means of Ward's method, using squared Euclidean distances as a measure of similarity. 


\section{Principal component analysis (PCA)/Factor Analysis (FA)}

In this research, PCA was applied to summarize the statistical correlation among water quality parameters. The concentrations of physico-chemical parameters and nutrients tend to differ greatly; as such, the statistical results should be highly biased by any parameter having a high concentration. Thus, each water quality parameter was standardized before PCA the analysis was performed in order to minimize the influence of different variables and their respective units of measurements. The calculations were performed based on the correlation matrix of chemical components, and the PCA scores were obtained from the standardized analytical data (Sayadi et al., 2014; Andrea et al., 2015).

\section{Comprehensive evaluation of water quality in the lake}

A comprehensive pollution index method has been applied to evaluate water quality qualitatively in many existing studies. The comprehensive pollution index can be calculated as follows (Yan et al., 2015):

$$
\mathrm{P}=1 / n ?{ }_{n=1}^{n}(\mathrm{Ci} / \mathrm{Si})
$$

where $P$ is comprehensive pollution index, $C_{i}$ is the measured concentration of the pollutant $\left(\mathrm{mg} \mathrm{L}^{-1}\right), S_{i}$ represents the limits allowed by the State Environmental Protection Administration (SEPA) in the particular country for water quality standard, and $\mathrm{n}$ is the number of selected pollutants (Bharti and Katyal, 2011; Zhao et al., 2012, Rubio-Arias et al., 2013, Yan et al., 2015 ). Ultimately, the values determined for $\mathrm{P}$ could be used to classify the water quality level of the lake (Table 3 ).

Table 3

Standard of surface water quality classification (WHO, 1996)

\begin{tabular}{|ll|}
\hline Comprehensive pollution index $(P)$ & Water quality level \\
\hline$\leq 0.20$ & I cleanness \\
\hline 0.20 to 0.40 & II sub-cleanness \\
\hline 0.41 to 1.00 & III slight pollution \\
\hline 1.01 to 2.00 & IV moderate pollution \\
\hline$\geq 2.01$ & V sever pollution \\
\hline
\end{tabular}

\section{Results}

\section{Spatial and temporal variations in Physico-chemical water quality parameters}

The average spatio-temporal values of physico-chemical water quality parameters in dry and wet seasons are given separately in Tables 4 and 5, respectively. The surface-water temperature measured in the study sites was ranged between 19.0 to $27.0^{\circ} \mathrm{C}$ and 18.0 to $27.0^{\circ} \mathrm{C}$ in dry and wet seasons, respectively where the highest value were measured at $\mathrm{B}$ and Ka while the lowest value were measured at $\mathrm{C}$ and $\mathrm{Fb}$ during dry and wet seasons, respectively. 
Table 4

Mean, mean standard error and range of the physicochemical parameters in dry season

\begin{tabular}{|c|c|c|c|c|c|c|c|c|}
\hline Site & & Temp & DO & $\mathrm{pH}$ & EC & TDS & SD & TA \\
\hline \multirow[t]{2}{*}{ B } & $\overline{\mathrm{X}} \pm$ Std. Err & $24.8 \pm 1.3$ & $7.3 \pm 1.8$ & $8.3 \pm 0.3$ & $385 \pm 38$ & $248 \pm 24$ & $24.6 \pm 0.5$ & $314 \pm 41$ \\
\hline & Range & $21-28$ & $4.8-12.4$ & $8-9$ & $289-521$ & 189-335 & $23-26$ & $216-425$ \\
\hline \multirow[t]{2}{*}{ C } & $\overline{\mathrm{x}} \pm$ Std. Err & $21.2 \pm 1.3$ & $5.2 \pm 1.1$ & $8.1 \pm 0.2$ & $408 \pm 43$ & $268 \pm 33.7$ & $27.7 \pm 1.3$ & $225 \pm 22$ \\
\hline & Range & $18-25$ & $4-8.4$ & $8-9$ & $337-558$ & 215-393 & $23-30$ & $184-300$ \\
\hline \multirow[t]{2}{*}{$\mathrm{Fa}$} & $\overline{\mathrm{x}} \pm$ Std. Err & $23.8 \pm 1.0$ & $6.8 \pm 1.7$ & $8.13 \pm 0.2$ & $639.73 \pm 114$ & $423.8 \pm 83$ & $26 \pm 0.7$ & $320 \pm 50$ \\
\hline & Range & $21-26$ & $4.2-11.2$ & $8-9$ & $376-1028$ & $249-720$ & $24-28$ & $200-425$ \\
\hline \multirow[t]{2}{*}{$\mathrm{Fb}$} & $\overline{\mathrm{x}} \pm$ Std. Err & 23. $5 \pm 1.4$ & $6.2 \pm 1.4$ & $7.56 \pm 0.1$ & $1233.6 \pm 107$ & $789.6 \pm 68.3$ & $25.8 \pm 0.6$ & $463 \pm 71.7$ \\
\hline & Range & $19-27$ & $2.6-9.3$ & $7-8$ & $1050-1650$ & $672-1056$ & $24-27$ & $200-625$ \\
\hline \multirow[t]{2}{*}{$\mathrm{Ka}$} & $\overline{\mathrm{x}} \pm$ Std. Err & $21.3 \pm 0.5$ & $4.4 \pm 1.5$ & $8.1 \pm 0.16$ & $382.6 \pm 39.4$ & $237.8 \pm 18.6$ & $24.4 \pm 1.8$ & $24 \pm 29$ \\
\hline & Range & $20-23$ & $2.5-9.2$ & $7-8$ & $307-543$ & 196-307 & $19-30$ & $156-325$ \\
\hline \multirow[t]{2}{*}{$\mathrm{Kb}$} & $\overline{\mathrm{x}} \pm$ Std. Err & $20.15 \pm 0.2$ & $5.5 \pm 0.6$ & $7.4 \pm 0.1$ & $170.7 \pm 14.3$ & $107.7 \pm 9$ & $21 \pm .7$ & $187 \pm 44$ \\
\hline & Range & $20-21$ & $4.0-7.0$ & $7-8$ & $134-204$ & $86-130$ & $19-23$ & $104-275$ \\
\hline \multirow[t]{2}{*}{ Ko } & $\overline{\mathrm{x}} \pm$ Std. Err & $24.2 \pm 1.3$ & $5.4 \pm 1.3$ & $7.4 \pm 0.8$ & $399 \pm 14.4$ & $254 \pm 10.5$ & $25.6 \pm 1.1$ & $330 \pm 38$ \\
\hline & Range & $21-28$ & $2.4-9.0$ & $7-9$ & $362-435$ & $219-278$ & $22-28$ & $200-425$ \\
\hline \multirow[t]{2}{*}{ Ma } & $\overline{\mathrm{x}} \pm$ Std. Err & $22.2 \pm 0.7$ & $4.4 \pm 0.6$ & $7.98 \pm 0.2$ & $404.1 \pm 43$ & $291.9 \pm 37.7$ & $27.8 \pm 1.8$ & $227.6 \pm 26$ \\
\hline & Range & $21-25$ & $3.3-6.5$ & $8-9$ & $333-576$ & 213-403 & $22-31$ & $160-300$ \\
\hline \multirow[t]{2}{*}{ Mb } & $\overline{\mathrm{x}} \pm$ Std. Err & $22.9 \pm 0.8$ & $7.6 \pm 1.6$ & $7.95 \pm 0.2$ & $424 \pm 625$ & $267 \pm 38$ & $21 \pm 0.71$ & $263 \pm 48$ \\
\hline & Range & $20-24$ & $3.8-10$ & $7-9$ & $203-584$ & $130-365$ & 19.00 & $100-375$ \\
\hline
\end{tabular}


Table 5

Mean, mean standard error and range of the physicochemical parameters in wet season

\begin{tabular}{|c|c|c|c|c|c|c|c|c|}
\hline Site & & Temp & DO & $\mathrm{pH}$ & EC & TDS & SD & TA \\
\hline \multirow[t]{2}{*}{ B } & $\overline{\mathrm{x}} \pm$ Std. Err & $22 \pm 0.5$ & $4.72 \pm 0.4$ & $8.59 \pm 0.1$ & $274.5 \pm 9$ & $175.7 \pm 58.2$ & $15.3 \pm 0.3$ & $207 \pm 6.3$ \\
\hline & Range & $21.5-23$ & $4.27-5.4$ & $8.4-8.7$ & $176-456$ & 113-292 & $15-16$ & $200-220$ \\
\hline \multirow[t]{2}{*}{ C } & $\overline{\mathrm{x}} \pm$ Std. Err & $21.2 \pm 0.3$ & $4.75 \pm 28$ & $8.57 \pm 0.1$ & $218 \pm 44$ & $147.8 \pm 37$ & $17.3 \pm 0.7$ & $168 \pm 6.1$ \\
\hline & Range & $20.7-22$ & $4.4-5.3$ & $8.4-8.7$ & $173-306$ & $110-222$ & $16-18$ & $160-180$ \\
\hline \multirow[t]{2}{*}{$\mathrm{Fa}$} & $\overline{\mathrm{x}} \pm$ Std. Err & $22 \pm 0.6$ & $4.4 \pm 0.3$ & $8.78 \pm 0.5$ & $353 \pm 89$ & $226 \pm 56$ & $18.6 \pm 0.7$ & $172 \pm 14$ \\
\hline & Range & $20.8-23$ & $3.95-4.8$ & 7.9-9.7 & $187-488$ & $120-312$ & $18-20$ & 148- 196 \\
\hline \multirow[t]{2}{*}{$\mathrm{Fb}$} & $\overline{\mathrm{x}} \pm$ Std. Err & $21 \pm 1.6$ & $6.2 \pm 0.7$ & $8.53 \pm 0.1$ & $370 \pm 98$ & $216 \pm 84$ & $19.6 \pm 0.7$ & $250 \pm 111$ \\
\hline & Range & $18-24$ & $4.9-7.2$ & 8.3-8.7 & $175-478$ & $49-306$ & $19-21$ & $120-472$ \\
\hline \multirow[t]{2}{*}{$\mathrm{Ka}$} & $\overline{\mathrm{x}} \pm$ Std. Err & $22 \pm 0.3$ & $3.1 \pm 0.3$ & $8.4 \pm 0.1$ & $230 \pm 41.4$ & $180 \pm 32$ & $16-1.2$ & $117-35$ \\
\hline & Range & $20-27$ & $2.4-3.5$ & $8.3-8.5$ & 183-312 & $117-221$ & $14-18$ & $80-188$ \\
\hline \multirow[t]{2}{*}{$\mathrm{Kb}$} & $\overline{\mathrm{x}} \pm$ Std. Err & $20 \pm 0.2$ & $2.6 \pm 0.6$ & $7.78 \pm 0.2$ & $101 \pm 17.9$ & $65 \pm 11.7$ & $17.3 \pm 0.9$ & $72.3 \pm .3$ \\
\hline & Range & $20-21$ & $1.4-3.6$ & 7.5-8.3 & $65-120$ & $42-78.3$ & $16-19$ & $72-73$ \\
\hline \multirow[t]{2}{*}{ Ko } & $\overline{\mathrm{x}} \pm$ Std. Err & $22.5 \pm 0.9$ & $4.8 \pm 0.3$ & $8.7 \pm 0.1$ & $381 \pm 101$ & $234 \pm 61$ & $18.3 \pm 0.9$ & $175 \pm 14.6$ \\
\hline & Range & $21-24$ & $4.35-5.3$ & $8.5-8.8$ & $179-496$ & $116-318$ & $17 .-20$ & $146-190$ \\
\hline \multirow[t]{2}{*}{$\mathrm{Ma}$} & $\overline{\mathrm{x}} \pm$ Std. Err & $23 \pm 0.1$ & $3.9 \pm 0.1$ & $8.6 \pm 0.1$ & $273 \pm 49$ & $153 \pm 21.3$ & $17 \pm 1.2$ & $130 \pm 24.9$ \\
\hline & Range & $22-23$ & $3.7-4.1$ & $8.6-8.61$ & $176-337$ & $113-185$ & $15-19$ & $100-180$ \\
\hline \multirow[t]{2}{*}{$\mathrm{Mb}$} & $\overline{\mathrm{x}} \pm$ Std. Err & $20.4 \pm 0.7$ & $4.8 \pm 0.8$ & $7.4 \pm 0.5$ & $120 \pm 3$ & $77 \pm 1.9$ & $18 \pm 1.7$ & $100 \pm 20$ \\
\hline & Range & $19.5-22$ & $3.4-5.8$ & $6.5-8.3$ & $115-126$ & $73.7-80.4$ & $15-21.0$ & $60-120$ \\
\hline
\end{tabular}

The level of dissolved oxygen (DO) ranged from 2.42 to $12.4 \mathrm{mg} \mathrm{L}^{-1}$ and 1.4 to $7.2 \mathrm{mg} \mathrm{L}^{-1}$ in dry and wet seasons, respectively (Tables 4 and 5). The lowest values in both seasons were at $\mathrm{K}_{\mathrm{o}}\left(2.4 \mathrm{mg} \mathrm{L}^{-1}\right)$ in dry and $\mathrm{K}_{\mathrm{b}}\left(1.4 \mathrm{mg} \mathrm{L}^{-1}\right)$ in wet seasons where as the highest values were at $\mathrm{B}\left(12.4 \mathrm{mg} \mathrm{L}^{-1}\right)$ in dry and $\mathrm{F}_{\mathrm{b}}\left(7.2 \mathrm{mg} \mathrm{L}^{-1}\right)$ in wet seasons, respectively. Whilst the $\mathrm{pH}$ values ranged from 7.0 to 9.0 and 6.5 to 9.7 in dry and wet seasons respectively (Tables 4 and 5).

The mean electrical conductivity $(\mathrm{EC})$ values in the study sites ranged from 134.0 to $1650 \mu \mathrm{sm}^{-1}$ in the dry season and 65.0 to $488 \mu \mathrm{S} \mathrm{cm}^{-1}$ in the wet season. Kb showed the lowest mean EC $\left(134 \mu \mathrm{Scm}^{-1}\right)$ in dry and $65 \mu \mathrm{S} \mathrm{cm}^{-1}$ in wet seasons while site $\mathrm{Fb}$ recorded the highest mean values of $1650 \mu \mathrm{S} \mathrm{cm}^{-1}$ in dry and Fa mean values $488 \mu \mathrm{S} \mathrm{cm}^{-1}$ in wet seasons, respectively (Tables 4 and 5). Total dissolved solid (TDS) ranged in the study sites from 119.77 to $746.80 \mathrm{mg} \mathrm{L}^{-1}$ with the low value in site $\mathrm{Kb}$ and the high value at site $\mathrm{Fb}$ while in the wet season it ranged from 129.5 to $547.76 \mathrm{mg} \mathrm{L}^{-1}$ at sites $\mathrm{Mb}$ and Fb respectively (Tables 4 and 5). The mean SD in Lake Ziway ranged from 0.20 to $0.22 \mathrm{~m}$, with mean values of $0.21 \mathrm{~m}$.

Total alkalinity (TA) in the study sites ranged from 100 to 625 and 60 to $472 \mathrm{mg} \mathrm{CaCO}_{3} \mathrm{~L}^{-1}$ in dry and wet seasons, respectively (Tables 4 and 5). Mb showed the lowest mean TA (100 $\left.\mathrm{mg} \mathrm{CaCO}_{3} \mathrm{~L}^{-1}\right)$ in dry and $60 \mathrm{mg} \mathrm{CaCO}_{3} \mathrm{~L}^{-1}$ in wet seasons while the highest mean values of TA ranged from 625 to $472 \mathrm{mg} \mathrm{CaCO}_{3} \mathrm{~L}^{-1}$ were observed in sampling site $\mathrm{Fb}$ in all seasons during entire study period.

\section{Nutrients analyses}

The spatial and temporal variations of nutrients are summarized in Tables 6 and 7. The mean $\mathrm{NO}_{3}-\mathrm{N}_{\text {concentration ranged from }}$ 0.1 to $5.26 \mathrm{mg} \mathrm{L}^{-1}$ and 0.01 to $0.86 \mathrm{mg} \mathrm{L}^{-1}$ in dry and wet seasons, respectively. The highest mean $\mathrm{NO}_{3}-\mathrm{N}$ was recorded at $\mathrm{Fb}$ in 
dry and $\mathrm{Kb}$ in wet season while the lowest values were in Ma during both seasons. $\mathrm{NO}_{2}-\mathrm{N}$ ranged from 0.06 to $2.89 \mathrm{mg} \mathrm{L}^{-1}$ in dry season and 0.20 to $1.8 \mathrm{mg} \mathrm{L}^{-1}$ in wet season during the study period (Tables 6 and 7). Low concentrations of $\mathrm{NO}_{2}-\mathrm{N}_{\text {were }}$ at $\mathrm{M}_{\mathrm{a}}$ in both dry and wet seasons whereas high concentration was at $F_{b}$ and $K_{b}$ in dry and wet seasons respectively (Tables 6 and 7 ).

Table 6

Mean, mean standard error and range of nutrient concentrations $\left(\mathrm{mg} \mathrm{L}^{-1}\right)$ measured in sampling sites at Lake Ziway in dry season

\begin{tabular}{|c|c|c|c|c|c|c|c|c|c|}
\hline Site & & TP & $\mathrm{PO}_{4}-\mathrm{P}$ & $\mathrm{NO}_{2}-\mathrm{N}$ & $\mathrm{NO}_{3}-\mathrm{N}$ & $\mathrm{NH}_{3}-\mathrm{N}$ & TIN & $\mathrm{TN}$ & $\mathrm{SiO}_{2}-\mathrm{Si}$ \\
\hline \multirow[t]{2}{*}{ B } & $\overline{\mathrm{x}} \pm$ Std. Err & $0.12 \pm 0.02$ & $0.06 \pm 0.01$ & $0.48 \pm 0.20$ & $0.17 \pm 0.04$ & $0.21 \pm 0.05$ & $0.85 \pm 0.25$ & $5.7 \pm .25$ & $46.2 \pm 6.2$ \\
\hline & Range & $0.06-0.15$ & $0.04-0.08$ & $0.188-1.3$ & $0.06-0.25$ & $0.1-0.35$ & $0.34-1.8$ & $4.9-6.4$ & $32-68$ \\
\hline \multirow[t]{2}{*}{ C } & $\overline{\mathrm{x}} \pm$ Std. Err & $0.14 \pm 0.02$ & $0.05 \pm 0.01$ & $0.29 \pm 0.05$ & $0.26 \pm 0.17$ & $0.17 \pm 0.03$ & $0.72 \pm 0.22$ & $9.1 \pm 0.65$ & $46.8 \pm 2.4$ \\
\hline & Range & $0.1-0.185$ & $0.03-0.07$ & $0.18-0.41$ & $0.01-0.91$ & $0.09-0.26$ & $0.29-1.5$ & $7.34-11.20$ & $39.5-54$ \\
\hline \multirow[t]{2}{*}{$\mathrm{Fa}$} & $\overline{\mathrm{X}} \pm$ Std. Err & $0.14 \pm 0.02$ & $0.05 \pm 0.01$ & $0.96 \pm 0.22$ & $0.38 \pm 0.13$ & $0.24 \pm 0.04$ & $1.6 \pm 0.36$ & $6.1 \pm .6$ & $46.8 \pm 4.9$ \\
\hline & Range & $0.105-0.23$ & $0.03-0.1$ & $0.6-1.8$ & $0.1-0.75$ & $0.15-0.35$ & $0.9-2.9$ & $4.5-8.3$ & $35-60$ \\
\hline \multirow[t]{2}{*}{$\mathrm{Fb}$} & $\overline{\mathrm{X}} \pm$ Std. Err & $0.19 \pm 0.05$ & $0.08 \pm 0.03$ & $1.7 \pm 0.44$ & $0.58 \pm 0.19$ & $0.29 \pm 0.05$ & $2.6 \pm 0.6$ & $8.1 \pm .56$ & 91.39 .8 \\
\hline & Range & $0.05-0.32$ & $0.04-0.16$ & $0.72-2.89$ & $0.08-0.97$ & $0.15-0.42$ & $1.0-4.2$ & $6.5-9.8$ & 56.9-114 \\
\hline \multirow[t]{2}{*}{$\mathrm{Ka}$} & $\overline{\mathrm{x}} \pm$ Std. Err & $0.13 \pm 0.02$ & $0.05 \pm 0.01$ & $0.35 \pm 0.08$ & $0.12 \pm 0.02$ & $0.22 \pm 0.05$ & $0.68 \pm 0.10$ & $7.1 \pm 1.1$ & $50.5 \pm 6.7$ \\
\hline & Minimum & $0.09-0.19$ & $0.04-0.07$ & $0.155-0.64$ & $0.08-0.18$ & $0.10-0.4$ & $0.40-0.95$ & $5.0-11$ & $40.1-77$ \\
\hline \multirow[t]{2}{*}{$\mathrm{Kb}$} & $\overline{\mathrm{X}} \pm$ Std. Err & $0.17 \pm 0.03$ & $0.05 \pm 0.01$ & $0.34 \pm 0.03$ & $0.22 \pm 0.05$ & $0.34 \pm 0.03$ & $0.89 \pm 0.08$ & $9.2 \pm 1.3$ & $68 \pm 7.8$ \\
\hline & Range & $0.08-0.24$ & 0.04-0.09 & $0.24-0.42$ & $0.07-0.35$ & $0.24-0.42$ & $0.76-1.2$ & 14-Jul & $43-88.7$ \\
\hline \multirow[t]{2}{*}{ Ko } & $\overline{\mathrm{x}} \pm$ Std. Err & $0.12 \pm 0.02$ & $0.05 \pm 0.01$ & $0.32 \pm 0.09$ & $0.10 \pm 0.03$ & $0.2 \pm 0.04$ & $0.62 \pm 0.14$ & $9.7 \pm .42$ & $39 \pm 3.4$ \\
\hline & Range & 0.07-0.19 & $0.04-0.07$ & $0.05 \pm 0.188$ & $0.01-0.18$ & $0.09-0.3$ & $0.3-1.2$ & $8.5-11$ & $30-47$ \\
\hline \multirow[t]{2}{*}{$\mathrm{Ma}$} & $\overline{\mathrm{x}} \pm$ Std. Err & $0.14 \pm 0.02$ & $0.05 \pm 0.01$ & $0.23 \pm 0.08$ & $0.10 \pm 0.02$ & $0.17 \pm 0.03$ & $0.55 \pm 0.08$ & $6.3 \pm .49$ & $49 \pm 3.8$ \\
\hline & Range & $0.09-0.2$ & $0.04-0.06$ & $0.1-0.53$ & $0.04-0.14$ & $0.114-0.3$ & $0.35-0.8$ & $4.8-7.6$ & $38-62$ \\
\hline \multirow[t]{2}{*}{$\mathrm{Mb}$} & $\overline{\mathrm{x}} \pm$ Std. Err & $0.97 \pm 0.75$ & $0.06 \pm 0.01$ & $0.41 \pm 0.17$ & $0.28 \pm 0.19$ & $0.41 \pm 0.17$ & $1.3 \pm 0.53$ & $9.4 \pm 1.2$ & $61.3 \pm 3.9$ \\
\hline & Range & $0.2-3.95$ & $0.04-0.08$ & $0.06-1.1$ & $0.03-1.1$ & $0.1-1.1$ & $0.21-3.2$ & $5.6-13$ & $50.8-73$ \\
\hline
\end{tabular}


Table 7

Mean, mean standard error and range of nutrient concentrations $\left(\mathrm{mg} \mathrm{L}^{-1}\right)$ measured in sampling sites at Lake Ziway in wet season

\begin{tabular}{|c|c|c|c|c|c|c|c|c|c|}
\hline Site & & $\mathrm{TP}(\mathrm{mg} / \mathrm{L})$ & $\mathrm{PO}_{4}-\mathrm{P}$ & $\mathrm{NO}_{2}-\mathrm{N}$ & $\mathrm{NO}_{3}-\mathrm{N}$ & $\mathrm{NH}_{3}-\mathrm{N}$ & TIN & TN & $\mathrm{SiO}_{2}-\mathrm{Si}$ \\
\hline \multirow[t]{2}{*}{ B } & $\begin{array}{l}\overline{\mathrm{X}} \pm \\
\text { Std. } \\
\text { Err }\end{array}$ & $0.35 \pm 0.1$ & $0.046 \pm 0.01$ & $0.47 \pm 0.06$ & $0.15 \pm 0.03$ & $0.11 \pm 0.02$ & $0.73 \pm 0.08$ & $5.13 \pm 1.20$ & $35.5 \pm 11.60$ \\
\hline & Range & $0.21-0.42$ & $0.04-0.06$ & $0.35-0.53$ & $0.08-0.20$ & $0.07-0.13$ & $0.57-0.86$ & $2.8-7.00$ & $12.37-47.30$ \\
\hline \multirow[t]{2}{*}{ C } & $\begin{array}{l}\overline{\mathrm{X}} \pm \\
\text { Std. } \\
\text { Err }\end{array}$ & $0.38 \pm 0.023$ & $0.05 \pm 0.01$ & $0.33 \pm 0.12$ & $0.17 \pm 0.12$ & $0.09 \pm 0.01$ & $0.59 \pm 0.24$ & $6.02 \pm 0.26$ & $43.6 \pm .72$ \\
\hline & Range & $0.34-0.41$ & $0.03-0.08$ & $0.21-0.57$ & $0.05-0.41$ & $0.08-0.10$ & $0.352-1.1$ & $5.60-6.5$ & $42.9-45.1$ \\
\hline \multirow[t]{2}{*}{$\mathrm{Fa}$} & $\begin{array}{l}\overline{\mathrm{X}} \pm \\
\text { Std. } \\
\text { Err }\end{array}$ & $0.29 \pm 0.12$ & $0.05 \pm 0.01$ & $0.74 \pm 0.22$ & $0.26 \pm 0.12$ & $0.09 \pm 0.03$ & $1.1 \pm 0.33$ & $7.0 \pm 0.81$ & $36 \pm 7.5$ \\
\hline & Range & $0.18-0.52$ & $0.04-0.07$ & $0.43-1.2$ & $0.03-0.39$ & $0.03-0.14$ & $0.48-1.62$ & $5.6-8.4$ & $22.2-47.7$ \\
\hline \multirow[t]{2}{*}{$\mathrm{Fb}$} & $\begin{array}{l}\overline{\mathrm{X}} \pm \\
\text { Std. } \\
\text { Err }\end{array}$ & $0.42 \pm 0.175$ & $0.11 \pm 0.04$ & $0.89 \pm 0.44$ & $0.44 \pm 0.19$ & $0.09 \pm 0.04$ & $1.42 \pm 0.62$ & $6.66 \pm 0.53$ & $39.2 \pm 26$ \\
\hline & Range & $0.17-0.75$ & $0.04-0.16$ & $0.34-1.8$ & $0.17-0.80$ & $0.02-0.15$ & $0.75-2.7$ & $5.6-7.4$ & 5.8-90.5 \\
\hline \multirow[t]{2}{*}{$\mathrm{Ka}$} & $\begin{array}{l}\overline{\mathrm{X}} \pm \\
\text { Std. } \\
\text { Err }\end{array}$ & $0.23 \pm 0.02$ & $0.05 \pm 0.01$ & $0.84 \pm 0.16$ & $0.47 \pm 0.04$ & $0.09 \pm 0.03$ & $1.39 \pm .18$ & $7.6 \pm 0.43$ & $37.9 \pm 4.68$ \\
\hline & Range & $0.20-0.27$ & $0.04-0.07$ & $0.5-1.1$ & $0.4-0.54$ & $0.03-0.12$ & $1.1 \pm 1.7$ & $7-8.4$ & $30.3-46.45$ \\
\hline \multirow[t]{2}{*}{ Kb } & $\begin{array}{l}\overline{\mathrm{X}} \pm \\
\text { Std. } \\
\text { Err }\end{array}$ & $0.73 \pm 0.27$ & $0.06 \pm 0.01$ & $1.2 \pm 0.20$ & $0.86 \pm 0.22$ & $0.15 \pm 0.10$ & $2.2 \pm .50$ & $8.1 \pm 0.86$ & $38.15 \pm 17.10$ \\
\hline & Range & $0.24-1.2$ & $0.05-0.08$ & $0.89-1.6$ & $0.52-1.3$ & $0.05-0.3$ & $1.5-3.1$ & $7-9.8$ & $11.24-70$ \\
\hline \multirow[t]{2}{*}{ Ko } & $\begin{array}{l}\overline{\mathrm{X}} \pm \\
\text { Std. } \\
\text { Err }\end{array}$ & $0.27 \pm 0.08$ & $0.05 \pm 0.01$ & $0.42 \pm 0.12$ & $0.20 \pm 0.04$ & $0.08 \pm 0.02$ & $0.7 \pm 0.12$ & $12 \pm 1.9$ & $34.3 \pm 11$ \\
\hline & Range & $0.12-0.376$ & $0.04-0.07$ & $0.2-0.6$ & $0.1-0.3$ & $0.05-0.1$ & $0.5-0.9$ & $8.4-14$ & $12.6-48.2$ \\
\hline \multirow[t]{2}{*}{ Ma } & $\begin{array}{l}\bar{X} \pm \\
\text { Std. } \\
\text { Err }\end{array}$ & $0.24 \pm 0.04$ & $0.06 \pm 0.02$ & $0.76 \pm 0.06$ & $0.23 \pm 0.11$ & $0.08 \pm 0.02$ & $1.06 \pm 0.14$ & $6.1 \pm .55$ & $42.62 \pm 1.9$ \\
\hline & Range & $0.19-0.33$ & 0.04-0.082 & $0.66-0.86$ & $\begin{array}{l}0.01- \\
0.369\end{array}$ & $0.03-0.11$ & $0.8-1.3$ & $4.97-7$ & $38.96-45.42$ \\
\hline \multirow[t]{2}{*}{ Mb } & $\begin{array}{l}\overline{\mathrm{X}} \pm \\
\text { Std. } \\
\text { Err }\end{array}$ & $1.0 \pm 0.30$ & $0.09 \pm 0.02$ & $1.02 \pm .2$ & $0.50 \pm 0.24$ & $0.16 \pm 0.06$ & $1.66 \pm .48$ & $13.5 \pm 4.5$ & $39.1 \pm 14.72$ \\
\hline & Range & $0.47-1.5$ & $0.06-0.12$ & $0.7-1.42$ & $0.02-0.75$ & $0.05-0.23$ & $0.76-2.4$ & $5.6-21$ & $11.2-61.2$ \\
\hline
\end{tabular}

Ammonia nitrogen $\left(\mathrm{NH}_{3}-\mathrm{N}\right)$ concentration ranged from 0.17 to $0.29 \mathrm{mg} \mathrm{L}^{-1}$ in dry and 0.08 to $0.15 \mathrm{mg} \mathrm{L}^{-1}$ in wet season with the lowest concentrations at $C$ and $M_{a}$ in dry and $K_{o}$ and $M_{a}$ in wet seasons while the highest values in $F_{b}$ and $K_{b}$ in dry and wet seasons respectively (Tables 6 and 7). The mean total nitrogen (TN) concentration ranged from 5.69 to $12.21 \mathrm{mg} \mathrm{L}^{-1}$ in dry and 4.98 to $12.0 \mathrm{mg} \mathrm{L}^{-1}$ in wet season. The highest concentrations were at $\mathrm{K}_{\mathrm{o}}$ in dry and at $\mathrm{F}_{\mathrm{b}}$ in wet season whereas the lowest concentrations were at B in both seasons (Table 6 and 7). 
Soluble reactive phosphorus (SRP) ranged from 0.05 to $0.08 \mathrm{mg} \mathrm{L}^{-1}$ and showed similar concentrations for lower values for most of the sampling sites and high values at $F_{b}$ in the dry season, while in the wet season it ranged from 0.05 to $0.12 \mathrm{mg} \mathrm{L}^{-1}$ (Tables 6 and 7). Most sites have also similar concentrations in the wet season and only Site $F_{b}$ had highest values. Similarly, the mean TP concentrations ranged from 0.12 to $0.97 \mathrm{mg} \mathrm{L}^{-1}$ and 0.23 to $1.02 \mathrm{mg} \mathrm{L}^{-1}$ in dry and wet seasons respectively (Tables 6 and 7 ). Mean TP concentration was highest at $\mathrm{M}_{\mathrm{b}}$ in both seasons whereas the lowest concentrations were at $B$ and $\mathrm{K}_{\mathrm{o}}$ in $\mathrm{dry}_{\mathrm{a}}$ and $\mathrm{K}_{\mathrm{a}}$ in wet seasons.

The concentration of $\mathrm{SiO}_{2}$-Si ranged from 39.4 to 91.3 and 35.5 to $42.6 \mathrm{mg} \mathrm{L}^{-1}$ with mean values of 55.4 and $38.5 \mathrm{mg} \mathrm{L}^{-1}$ in dry and wet seasons, respectively (Tables 6 and 7) where the highest and lowest concentrations were noticed during the dry and wet seasons, respectively (Tables 6 and 7). Significant fluctuations in the mean $\mathrm{SiO}_{2}$-Si concentrations were observed in both seasons showed that the fluctuations in it over the different seasons and across the different sampling sites were significant in the Lake.

\section{Multivariate analysis}

\section{Principle component analysis (PCA)}

Four components of PCA analysis showed $88.10 \%$ of the variance in the data set of the wet season, as the eigenvectors classified the 15 physico-chemical parameters into four groups. $\mathrm{PC}_{1}$ (38.93\% of the total variance in the data set) has strong positive loadings on TP, $\mathrm{NH}_{3}-\mathrm{N}, \mathrm{NO}_{2}-\mathrm{N}, \mathrm{NO}_{3}-\mathrm{N}, \mathrm{TIN}, \mathrm{pH}$ and $\mathrm{SD}$ (Table 8). The second component $\left(\mathrm{PC}_{2}\right)$ accounted for $24.02 \%$ of the total variance measured, demonstrated strong positive loadings for TN, EC, TDS and TA and the third component $\left(\mathrm{PC}_{3}\right)$ demonstrated $16.76 \%$ of the total variance and have strong positive loadings on $\mathrm{SiO}_{2}-\mathrm{Si}, \mathrm{PO}_{4}-\mathrm{P}, \mathrm{DO}$ and temperature, while, the fourth component $\left(\mathrm{PC}_{4}\right)$ accounts only $8.39 \%$ of the total variance in the season (Table 8$)$. 
Table 8

The Factor loadings values and explained variance of water quality in two seasons (positive and negative strong correlations are marked bold)

\begin{tabular}{|c|c|c|c|c|c|c|c|c|c|}
\hline Dry season & & & & & Wet season & & & & \\
\hline Parameters & PC1 & PC 2 & PC3 & PC 4 & Parameters & PC1 & PC2 & PC3 & PC 4 \\
\hline TP & 0.065 & -0.69 & 0.48 & 0.10 & TP & 0.92 & -0.18 & 0.21 & 0.23 \\
\hline P04 & 0.93 & -0.16 & 0.13 & -0.03 & PO4 & 0.15 & -0.18 & 0.85 & 0.37 \\
\hline $\mathrm{NH} 3$ & 0.907 & -0.04 & 0.27 & -0.11 & $\mathrm{NH} 3$ & 0.85 & -0.38 & 0.32 & 0.05 \\
\hline NO2 & 0.966 & 0.10 & -0.07 & -0.09 & NO2 & 0.88 & 0.09 & -0.33 & -0.15 \\
\hline NO3 & 0.963 & -0.04 & -0.21 & 0.10 & NO3 & 0.90 & -0.005 & 0.03 & -0.34 \\
\hline TIN & 0.98 & -0.01 & -0.17 & 0.06 & TIN & 0.94 & 0.03 & -0.14 & -0.235 \\
\hline $\mathrm{TN}$ & -0.097 & -0.32 & 0.18 & 0.88 & $\mathrm{TN}$ & 0.56 & 0.68 & -0.28 & 0.20 \\
\hline $\mathrm{SiO} 2$ & 0.791 & -0.52 & -0.29 & -0.05 & $\mathrm{SiO} 2$ & 0.11 & -0.10 & -0.62 & 0.49 \\
\hline Temp & 0.283 & 0.79 & 0.43 & -0.09 & Temp & -0.11 & 0.19 & 0.63 & -0.62 \\
\hline DO & 0.349 & -0.42 & 0.76 & -0.09 & DO & 0.08 & 0.55 & 0.64 & 0.40 \\
\hline $\mathrm{PH}$ & -0.373 & 0.76 & 0.49 & 0.08 & $\mathrm{pH}$ & -0.85 & 0.13 & 0.01 & -0.17 \\
\hline EC & 0.963 & 0.16 & -0.02 & 0.09 & EC & -0.25 & 0.96 & -0.07 & 0.03 \\
\hline TDS & 0.955 & 0.17 & -0.05 & 0.08 & TDS & -0.26 & 0.95 & -0.087 & 0.03 \\
\hline$S D$ & 0.035 & 0.66 & -0.34 & 0.32 & SD & 0.61 & 0.58 & -0.21 & -0.16 \\
\hline TA & 0.801 & 0.54 & 0.20 & 0.11 & TA & 0.44 & 0.63 & 0.43 & 0.03 \\
\hline Eigen value & 7.97 & 3.05 & 1.66 & 0.96 & Eigen value & 5.84 & 3.60 & 2.52 & 1.26 \\
\hline$\%$ variance & 53.133 & 20.34 & 11.09 & 6.41 & $\%$ variance & 38.93 & 24.02 & 16.76 & 8.39 \\
\hline $\begin{array}{l}\% \text { Cumulative } \\
\text { variance }\end{array}$ & 53.133 & 73.47 & 84.56 & 90.97 & $\begin{array}{l}\% \text { cumulative } \\
\text { variance }\end{array}$ & 38.93 & 62.95 & 79.71 & 88.10 \\
\hline
\end{tabular}

The dry season PCA analysis showed that four principal components (PCs) represented about $90.97 \%$ of the total variation in the entire dataset. The first $\mathrm{PC}$ accounted for $53.4 \%$ of the total variations between sites and comprised of the following parameters: nutrients $\left(\mathrm{NH}_{3}-\mathrm{N}, \mathrm{NO}_{2}-\mathrm{N}, \mathrm{NO}_{3}-\mathrm{N}, \mathrm{TIN}, \mathrm{PO}_{4}-\mathrm{P}, \mathrm{SiO}_{2}-\mathrm{Si}\right)$, TDS, EC, TA. The second PC accounted for $20.34 \%$ of the total variance and had strong positive loading with temperature, $\mathrm{pH}, \mathrm{TP}$ and $\mathrm{SD}$ as the associated parameters. The third PC explained $11.09 \%$ of the total variations between sites comprising only DO. Scree plot showed the eigenvalues sorted from large to small as a function of the principal components number after the fourth PC (Figure 2a and b).

The bi-plot of PCs associated with nutrients $\left(\mathrm{NH}_{3}-\mathrm{N}, \mathrm{NO}_{3}-\mathrm{N}, \mathrm{NO}_{2}-\mathrm{N}, \mathrm{SiO}_{2}-\mathrm{Si}\right.$ and $\left.\mathrm{PO}_{4}-\mathrm{P}\right), \mathrm{EC}$ and TDS characterizing Fb sampling site from axis 1 (Figure 3 ) and Fa distinctiveness was attributed to temperature, SD and TA. The parameter influencing the distinction in the $\mathrm{B}$ site from axis 2 was mainly $\mathrm{pH}$ while $\mathrm{Mb}$ site from axis 2 was influenced by DO, TN and TP in the dry season.

The bio-plot of PCs associated with nutrients $\left(\mathrm{NH}_{3}-\mathrm{N}, \mathrm{NO}_{3}-\mathrm{N}, \mathrm{NO}_{2}-\mathrm{N}, \mathrm{SiO}_{2}-\mathrm{Si}, \mathrm{TIN}, \mathrm{PO}_{4}-\mathrm{P}\right.$ and TP), which were the key parameters characterizing the $\mathrm{Mb}$ and $\mathrm{Kb}$ sampling sites (Figure 4) and Fa distinctiveness was attributed to temperature, TDS, EC and DO. The parameter influencing the distinction in the $\mathrm{K}_{\mathrm{o}}$ site was mainly $\mathrm{pH}$ while Fb site was influenced by DO, TN, TA and SD in the wet season.

For the two temporal clusters, $90.97 \%$ and $88.10 \%$ of the variances in dry and wet seasons, respectively, were explained by the four main factors. 
A dendrogram of sampling sites obtained by Ward's method is shown in Figure 5. Nine sampling sites were divided into three groups. Cluster 1 corresponded to site Fb, which was located in the western part of the lake. Cluster 2 included site Kb, which were located in the eastern portion of the lake. Cluster 3 contained sites $\mathrm{Fa}, \mathrm{K}_{\mathrm{o}}$ and $\mathrm{B}$ the western part of the lake, $\mathrm{C}$ which was in the lake central station; site $\mathrm{Mb}$ and $\mathrm{Ma}$ in northern part of the lake and Ka was in the eastern part of the lake.

The wet season sampling sites classification performed by the use of cluster analysis grouped all the nine sampling sites of the basin into three statistically significant clusters (Figure 6).

\section{Comprehensive evaluation of Lake Ziway water quality analysis}

The values of the comprehensive pollution index were 1.8, 1.0, 1.01 and 1.08 for sites Fb, Fa, B and Mb respectively (Table 9), which demonstrated moderate pollution in dry season while sampling sites of $\mathrm{Ka}$, $\mathrm{Ma}$, $\mathrm{C}$, and $\mathrm{Kb}$ have pollution index of $0.71,0.69$, $0.81,0.79$ and 0.84 respectively, which demonstrated slight pollution in the same season. However, in the wet season, the values of the comprehensive pollution index ranged from 0.38 to 0.68 which demonstrated slight pollution of the whole sampling sites.

Table 9

Single pollution index and comprehensive pollution index of nine sampling sites in some selected water quality parameters in dry and wet seasons

\begin{tabular}{|llllllllllllll|}
\hline \multicolumn{3}{|c}{ Dry season } & & & & \multicolumn{7}{c|}{ Wet season } \\
\hline Site & $\mathrm{P}_{\mathrm{PO4}}$ & $\mathrm{P}_{\mathrm{NH} 3}$ & $\mathrm{P}_{\mathrm{NO2} 2}$ & $\mathrm{P}_{\mathrm{NO3}}$ & $\mathrm{P}_{\mathrm{DO}}$ & $\mathbf{P}$ & $\mathrm{P}_{\mathrm{PO4}}$ & $\mathrm{P}_{\mathrm{NH} 3}$ & $\mathrm{P}_{\mathrm{NO} 2}$ & $\mathrm{P}_{\mathrm{NO} 3}$ & $\mathrm{P}_{\mathrm{DO}}$ & $\mathbf{P}$ \\
\hline $\mathrm{Fb}$ & 0.83 & 0.20 & 1.91 & 0.53 & 1.20 & $\mathbf{1 . 8 0}$ & 0.60 & 0.06 & 0.99 & 0.53 & 1.21 & $\mathbf{0 . 6 8}$ \\
\hline $\mathrm{Fa}$ & 0.48 & 0.16 & 1.06 & 0.04 & 1.09 & $\mathbf{1 . 0}$ & 0.50 & 0.06 & 0.93 & 0.04 & 1.02 & $\mathbf{0 . 5 1}$ \\
\hline $\mathrm{B}$ & 0.55 & 0.14 & 0.53 & 0.02 & 1.33 & $\mathbf{1 . 0 1}$ & 1.10 & 0.07 & 0.37 & 0.02 & 1.18 & $\mathbf{0 . 5 5}$ \\
\hline $\mathrm{Ka}$ & 0.50 & 0.14 & 0.39 & 0.01 & 0.89 & $\mathbf{0 . 7 1}$ & 0.50 & 0.06 & 0.52 & 0.01 & 0.78 & $\mathbf{0 . 3 8}$ \\
\hline $\mathrm{Ma}$ & 0.51 & 0.11 & 0.31 & 0.01 & 0.88 & $\mathbf{0 . 6 9}$ & 0.57 & 0.05 & 0.84 & 0.01 & 0.84 & $\mathbf{0 . 4 6}$ \\
\hline $\mathrm{Ko}$ & 0.51 & 0.13 & 0.36 & 0.01 & 1.07 & $\mathbf{0 . 8 1}$ & 0.50 & 0.05 & 0.47 & 0.01 & 1.03 & $\mathbf{0 . 4 1}$ \\
\hline $\mathrm{C}$ & 0.46 & 0.11 & 0.32 & 0.03 & 1.04 & $\mathbf{0 . 7 9}$ & 0.51 & 0.06 & 0.82 & 0.03 & 0.97 & $\mathbf{0 . 4 8}$ \\
\hline $\mathrm{Kb}$ & 0.52 & 0.12 & 0.37 & 0.02 & 1.10 & $\mathbf{0 . 8 4}$ & 0.59 & 0.10 & 1.32 & 0.02 & 0.70 & $\mathbf{0 . 5 5}$ \\
\hline $\mathrm{Mb}$ & 0.62 & 0.15 & 0.45 & 0.03 & 1.43 & $\mathbf{1 . 0 8}$ & 0.85 & 0.10 & 1.13 & 0.03 & 1.25 & $\mathbf{0 . 6 7}$ \\
\hline
\end{tabular}

\section{Temporal variation of water quality}

Significant temporal variations were observed in physico-chemical parameters and nutrients of Lake Ziway water quality where most of the physicochemical parameters have significantly higher values in the dry season as compared to wet season $(P<0.05)$ (Table 10) 
Table 10

Paired samples Test for dry and wet seasons

\begin{tabular}{|c|c|c|c|c|c|}
\hline \multicolumn{6}{|c|}{ Paired Samples Test } \\
\hline & & \multicolumn{3}{|c|}{ Paired Differences } & \multirow[t]{2}{*}{ Sig. (2-tailed) } \\
\hline & & Mean & Std. Deviation & Std. Error Mean & \\
\hline Pair 1 & TP in dry - TP in Wet & -0.20 & 0.15 & 0.05 & 0.00 \\
\hline Pair 2 & $\mathrm{PO}_{4}-\mathrm{P}$ in dry - $\mathrm{PO} 4-\mathrm{P}$ in wet & -0.01 & 0.02 & 0.01 & 0.27 \\
\hline Pair 3 & $\mathrm{NH}_{3}-\mathrm{N}$ in Dry - NH3-N wet & 0.11 & 0.05 & 0.02 & 0.00 \\
\hline Pair 4 & $\mathrm{NO}_{2}-\mathrm{N}$ in Dry - NO2-N in wet & -0.171 & 0.502 & 0.17 & 0.34 \\
\hline Pair 5 & $\mathrm{NO}_{3}-\mathrm{N}$ in Dry - NO3-N in wet & 0.48 & 1.68 & 0.56 & 0.42 \\
\hline Pair 6 & TIN in dry - TIN in wet & 0.41 & 2.14 & 0.71 & 0.58 \\
\hline Pair 7 & TN in dry - TN in wet & 0.57 & 2.79 & 0.93 & 0.56 \\
\hline Pair 8 & $\mathrm{SiO}_{2}-\mathrm{Si}$ in dry - SiO2- $\mathrm{Si}$ in wet & 16.88 & 15.68 & 5.23 & 0.01 \\
\hline Pair 9 & Temp in dry - Temp in wet & 1.68 & 1.22 & 0.416 & 0.00 \\
\hline Pair 10 & DO in dry - DO in wet & 0.58 & 0.60 & 0.20 & 0.02 \\
\hline Pair 11 & $\mathrm{PH}$ in dry - DO in wet & 2.97 & 0.97 & 0.32 & 0.00 \\
\hline Pair 12 & EC in dry - EC in wet & 109.04 & 112.82 & 37.61 & 0.02 \\
\hline Pair 13 & TDS in dry - TDS in wet & 73.10 & 71.67 & 23.89 & 0.02 \\
\hline Pair 14 & SD in dry - SD in wet & 7.73 & 2.11 & 0.70 & 0.00 \\
\hline Pair 15 & TA in dry - TA in wet & 93.65 & 85.24 & 28.41 & 0.01 \\
\hline
\end{tabular}

\section{Discussion}

\section{Spatial and temporal variations Physico-chemical water quality of Lake Ziway}

The spatial and temporal variation of mean water temperature in Lake Ziway was not significant $(p>0.05)$ during the study period. The mean temperature of the lake water was $23.0^{\circ} \mathrm{C}$ in both seasons, which is almost similar to the previously reports (Tilahun and Ahlgren, 2010) but lower than the value reported by Tamire and Mengistou (2012). Lake Ziway has narrow seasonal fluctuations in water temperature due to the lake is shallow tropical lake.

The lowest $\mathrm{DO}$ values in dry season at $\mathrm{K}_{\mathrm{o}}$ was attributed to human impacts like fishing, car and human washing while the low DO level at $\mathrm{Kb}$ in the wet season was attributed to its muddy water nature with agricultural runoff. The highest values of DO at sampling sites B in dry season might be attributed to the presence of macrophytes and phytoplankton with higher biomass and abundance than other sites (Tamire and Mengistu, 2012). The high values of DO at sampling site Fb in the wet season could be probably due to high dilution. The overall mean DO concentration in this study $\left(5.00 \mathrm{mg} \mathrm{L}^{-1}\right)$ is much lower than the value reported by Roba (2008), (8.72 $\mathrm{mg} \mathrm{L}^{-1}$ ). Tadele (2012) has also reported the DO concentration of $1.4 \mathrm{mg} \mathrm{L}^{-1}$ around the floriculture effluent which is smaller than the present study. Concentrations below $4.0 \mathrm{mg} \mathrm{L}^{-1}$ adversely affect aquatic life (FEPA, 2003). The value of DO in this study is within the EU (1998) and WHO (1996) permissible limits. According to EU (1998) and WHO (1996), the standard for DO value for fisheries and aquatic life is between 5.0 to $9.0 \mathrm{mg} \mathrm{L}^{-1}$. 
The overall mean $\mathrm{pH}$ value of the lake water was 8.10 which is in a close agreement with previous data reported by Roba (2008), Tilahun and Ahlgren (2010) and Tamire and Mengistou (2012), who reported 8.39 and 8.65, 8.44, respectively. However, significant temporal variation was noted during the study as significantly lower value was measured during the rainy season than dry season. The $\mathrm{pH}$ value could mainly be controlled by freshwater swamp exudates that regulate the acidity of the water body. A $\mathrm{pH}$ range of 6 to 8.5 is normal according to the APHA, 1999. In general, the pH of Ziway Lake water is within the acceptable range according to (WHO, 1996).

The overall mean values of EC (404.30 $\left.\mu \mathrm{S} \mathrm{cm}^{-1}\right)$ was comparable with previous report of Gebre-Mariam et al. (2002); Tilahun and Ahlgren (2010) and Tamire and Mengistou (2012) with EC values of 410, 478, $419.14 \mu \mathrm{S} \mathrm{cm}^{-1}$ respectively. Higher conductivity values were measured at the floriculture farming sites than other sampling sites could be attributed to the use of high amount of dissolved agrochemicals from effluents of floriculture industry (Tadele, 2012; Ayenew, 2005). For the present study, the EC values of different sampling sites were well below the WHO guideline values prescribed for drinking water purpose $\left(1500 \mu \mathrm{S} \mathrm{cm}{ }^{-1}\right)(\mathrm{WHO}$, 1996). Accordingly, the value of EC in different water samples could not be water quality problem of the study area. TDS also followed the same trend as that of EC as EC is sensitive to variations in dissolved solids, mostly mineral salts, and there were significantly lower value of EC and TDS during the main rainy season which may be because of dilution.

Similar result of mean SD values with this study $(0.21 \mathrm{~m})$ was reported by Tilahun (2006) which was $0.19 \mathrm{~m}$. however, the range values of this study $(0.20$ to $0.22 \mathrm{~m}$ ) was smaller than the valued which ranged from 0.20 to $0.35 \mathrm{~m}$ and 0.4 to $1.06 \mathrm{~m}$ reported by Dagne et al. (2008) and Tilahun (1988) in earlier time, respectively. Moreover, Degne (2010) also reported that the mean SD value was $0.29 \mathrm{~m}$ in Lake Ziway. The declining trend in SD reading is one of the indications which suggest the increasing trend in turbidity of the lake, which can be mainly attributed to catchment degradation and siltation.

Tilahun and Ahlgren (2010) reported that the mean value of TA in the Lake was $247.5 \mathrm{mg} \mathrm{CaCO}_{3} \mathrm{~L}^{-1}$ which was similar value in this study in dry season $\left(239.3 \mathrm{mg} \mathrm{CaCO}_{3} \mathrm{~L}^{-1}\right)$ where as the value in the wet season $\left(154.6 \mathrm{mg} \mathrm{CaCO}_{3} \mathrm{~L}^{-1}\right)$ was very low. In the lake, TA was solely due to bicarbonates and carbonate alkalinity that could be traced at any station during the entire period of study. According to Camacho et al. (2015) nutrient status classifications using TA, Lake Ziway can be considered nutrient rich. During all the seasons, fluctuations in TA across the sites were significant. TA has generally decreased in the wet seasons probably due to the dilution effect of the rains and fresh incoming runoffs (Singh et al., 2004; Ghafar et al., 2014).

\section{Nutrients analyses}

All the nutrient species analyzed in the surface water of the lake showed increased trend. The mean nitrate nitrogen values found in this study $\left(0.21 \mathrm{mg} \mathrm{L}^{-1}\right)$ was higher than those values $0.17,0.003,0.06 \mathrm{mg} \mathrm{L}^{-1}$ reported by Kebede et al. (1994), Tilahun and Ahlgren (2010), Tamire and Mengistu (2012) respectively. The increasing trend in nitrate concentration in the lake is probably because of nutrient enrichment of the littoral zone of the lake from anthropogenic sources from the catchment area. The mean nitrite nitrogen values found in this study $\left(0.5 \mathrm{mg} \mathrm{L}^{-1}\right)$ was also higher than the values reported by previous studies on the lake. For instance, Beneberu and Mengistu (2005) and Tamire and Mengistu (2012) has reported 0.06 and $0.01 \mathrm{mg} \mathrm{L}^{-1}$ nitrite nitrogen respectively. Relatively higher nitrite concentrations were measured near effluent of floriculture industry which could be due to the application of high amount of agrochemicals (Tadele, 2012). Comparatively, higher concentration of nitrite nitrogen value also measured in Lake Ziway than some other Ethiopian lakes for instance, Lake Hayq (Fetahi, 2010). The mean concentration of nitrite nitrogen in this study is beyond the concentration limit of the EU guide lines for drinking water (0.1 mg nitrite nitrogen $\left.\mathrm{L}^{-1}\right)$ (EU, 1998). Consequently, it might cause environmental concern due to its toxicity to aquatic biota as well as because of human health effects.

The mean concentration of $\mathrm{NH}_{3}-\mathrm{N}\left(0.121 \mathrm{mg} \mathrm{L}^{-1}\right)$ in this study is closely similar with relatively recent reports; by Tilahun, 2006 (0.111 $\left.\mathrm{mg} \mathrm{L}^{-1}\right)$, and Tamire and Mengistu, 2012 (0.143) but higher than that of earlier reports; for example, by Kebede et al., 1994 $\left(0.036 \mathrm{mg} \mathrm{L}^{-1}\right)$ indicating increasing trend. The mean TN concentration in both dry and wet season in this study is higher than the standard limit value even for eutrophic waters (APHA, 1999).

In addition, the mean SRP concentration $\left(0.06 \mathrm{mg} \mathrm{L}^{-1}\right)$ was higher than that of the pervious reported data of Kebede (1994), Gebre-Mariam (2002), Tilahun (2006), and Tamire (2012) which was 0.016, 0.01, 0.059 and $0.029 \mathrm{mg} \mathrm{L}^{-1}$, respectively. The 
measured concentration is also beyond the range of its threshold $\left(0.05\right.$ to $\left.0.1 \mathrm{mgL}^{-1}\right)$ as a nutrient for natural waters (Jeppesen et al., 1997). This is because in recent times Lake Ziway is exposed to anthropogenic activities due to over usage of agrochemicals like fertilizers, pesticides in which organic and inorganic pollutants releases and discharge of water from domestic sources, agricultural runoff, and horticulture including floriculture activities around the lake. Besides, the mean TP value of the lake water (0.311 $\mathrm{mg} \mathrm{L}^{-1}$ ) is higher than the previous reported data of Kebede et al., (1994), and Tilahun and Ahlgren (2010), which was 0.069 and $0.219 \mathrm{mg} \mathrm{L}^{-1}$ respectively. Higher TP concentration was also measured in this lake in this study as compared to that of other Ethiopian rift valley lakes like Lake Awasa and Chamo (Tilahun and Ahlgren, (2010). The increasing trend in TP is also probably because of nutrient enrichment of the lake from the highly agricultural activities around the lake watershed (Desta et al., 2016).

Higher concentration of $\mathrm{SiO}_{2}$-Si was found in dry season compared to wet season, this might be because of dilution in the wet season. Similar results were reported by Vessely et al. (2005). Significant fluctuations in mean $\mathrm{SiO}_{2}-\mathrm{Si}$ concentrations were observed over the different seasons and across the different sampling sites in the Lake. The range and mean concentration of $\mathrm{SiO}_{2}$ - $\mathrm{Si}$ in this study (39.36 to 91.29 and 35.53 to $42.62 \mathrm{mg} \mathrm{L}^{-1}$ with mean values of 55.4 and $38.5 \mathrm{mg} \mathrm{L}^{-1}$ in dry and wet seasons, respectively) is higher than that of the reports by previous studies. Gebre-Mariam (2002) reported that $\mathrm{SiO}_{2}$-Si concentrations of Lake Ziway ranged 13.4 to 31 and 14.7 to $37.5 \mathrm{mg} \mathrm{L}^{-1}$ with mean values of 19.0 and $22.9 \mathrm{mg} \mathrm{L}^{-1}$ in dry and wet seasons, respectively. The overall mean concentration of $\mathrm{SiO}_{2}-\mathrm{Si}\left(40.68 \mathrm{mg} \mathrm{L}^{-1}\right)$ in this study was higher than the previous reported values in the same lake and other Ethiopian rift valley Lakes, Awasa and Chamo by Tilahun and Ahlgren (2010) which was 23.8, 37.6 and $1.00 \mathrm{mg} \mathrm{L}^{-1}$ in Lake Ziway, Awasa and Chamo, respectively. In view of the high silica concentrations $\left(>10 \mathrm{mg} \mathrm{SiO}_{2} \mathrm{~L}^{-1}\right)$ commonly encountered in African lakes (Talling and Lemoalle, 1998), the lake might encounter some ecological changes especially towards higher Diatom productivity.

Generally, a pattern of low mean concentrations of $\mathrm{NH}_{3}-\mathrm{N}, \mathrm{NO}_{3}-\mathrm{N}, \mathrm{TN}, \mathrm{TIN}, \mathrm{SiO}_{2}-\mathrm{Si}$ in dry season have higher mean concentrations in wet season. This strongly indicated point source pollution for this parameter, which might be associated with industrial effluents, human interference, municipal discharge and animal waste (Meshesha et al., 2012). During dry season both decreased precipitation and increased agricultural withdraws for irrigation contributed to lower flows of those nutrients, however, $T P, \mathrm{PO}_{4}-\mathrm{P}$ and $\mathrm{NO}_{2}-\mathrm{N}$ were observed in a higher concentration during wet season. Similarly, Sridhar et al. (2015) noted that nutrients that have a high concentration during dry season than wet season tend to come from point sources whose supply is constant, whereas the inverse pattern can be attributed to non-point sources that are mobilized by high run-off during wet periods.

\section{Multivariate analysis}

\section{Principle component analysis (PCA)}

As indicated in the PCA analysis, $\mathrm{PC}_{1}$ has strong positive loadings on $\mathrm{NH}_{3}-\mathrm{N}, \mathrm{NO}_{2}-\mathrm{N}, \mathrm{NO}_{3}-\mathrm{N}_{2} \mathrm{PO}_{4}-\mathrm{P}, \mathrm{TP}, \mathrm{SiO}_{2}-\mathrm{Si}, \mathrm{TIN}, \mathrm{EC}$, TDS, TA and $\mathrm{SD}$ associated sampling sites $\mathrm{Mb}$ and $\mathrm{Kb}$ during wet season. The presence of nutrients in $\mathrm{PC}_{1}$ demonstrated the intense of agricultural activities in the environment of the lake ecosystem and this resulted in pollution with nutrients coming from fertilizers and pesticides (Meshesha et al., 2012).

One of the main sources of TP in runoff is soils with high phosphorus levels. In other words, the nutrient parameters, pH and SD account for similar patterns seen in lake water samples. This group of nutrient parameters also reflected the degree of eutrophication of the lake, suggesting that the anthropogenic pollution mainly from the discharge of domestic and agricultural wastes, industrial sewage and agricultural runoff (Meshesha et al., 2012). Moreover, it might be due to farmers use ammonium fertilizers and phosphate pesticides, and the lake receive ammonium via surface runoff and irrigation waters (Desta et al., 2016). Nitrate nitrogen source is due to numerous sources, such as, geologic deposits, natural organic matter decomposition and agricultural runoff (Leo et al., 2014). The second component ( $\mathrm{PC}_{2}$ ) demonstrated strong positive loadings for TN, EC, TDS and TA. The third components $\left(\mathrm{PC}_{3}\right)$ demonstrated strong positive loadings for $\mathrm{SiO}_{2}-\mathrm{Si}, \mathrm{PO}_{4}-\mathrm{P}, \mathrm{DO}$ and temperature. This factor indicates that $\mathrm{PO}_{4}-\mathrm{P}$ source is from domestic and agricultural wastes, detergents from industries whereas $\mathrm{SiO}_{2}-\mathrm{Si}$ is from bed rock materials and compounds containing silica from floriculture industry (Tadele, 2012), while, the fourth component $\left(\mathrm{PC}_{4}\right)$ had no strong loadings in any measured parameters. 
In the dry season the PCA performed on the correlation matrix of means of the analyzed water quality parameters by sites showed that four principal components (PCs) represented about $90.97 \%$ of the total variation in the entire dataset. The first PC accounted nutrients $\left(\mathrm{NH}_{3}-\mathrm{N}, \mathrm{NO}_{2}-\mathrm{N}, \mathrm{NO}_{3}-\mathrm{N}, \mathrm{TIN}, \mathrm{PO}_{4}-\mathrm{P}, \mathrm{SiO}_{2}-\mathrm{Si}\right), \mathrm{TDS}, \mathrm{EC}, \mathrm{TA}$ associated with $\mathrm{Fa}$ and $\mathrm{Fb}$ sampling sites. The high values in these sampling sites were attributed to the point pollution sources from floriculture industry in dry season.

The second PC had strong positive loading with temperature, $\mathrm{pH}, \mathrm{TP}$ and SD as the associated parameters. TP demonstrating that intense agricultural activity had occurred at the sampling site Fa and B, causing pollution due to fertilizers and pesticides (Meshesha et al., 2012). Singh et al. (2004) interpreted as nutrient pollution from anthropogenic sources, such as eutrophication from domestic wastewater, industrial effluents and agricultural activities. The third PC explained the total variations between sites comprising only DO in sampling site $\mathrm{Mb}$. The inverse relationship between temperature and $\mathrm{DO}$ is a natural process because it can hold less dissolved oxygen (Singh et al., 2004). The fourth PC explained site variations with TN only. Liu et al. (2003) classified the factor loadings as "strong," "moderate," and "weak," corresponding to absolute loading values of $>0.75,0.75$ to 0.50 , and 0.50 to 0.30 , respectively.

The bi-plot of PCs associated with nutrients $\left(\mathrm{NH}_{3}-\mathrm{N}, \mathrm{NO}_{3}-\mathrm{N}, \mathrm{NO}_{2}-\mathrm{N}, \mathrm{SiO}_{2}-\mathrm{Si}\right.$ and $\left.\mathrm{PO}_{4}-\mathrm{P}\right), \mathrm{EC}$ and TDS which were the key parameters characterizing the Fb sampling site (Figure 3), which were due to the floriculture effluents (Tadele, 2012, Tamire and Mengistu, 2012) and Fa distinctiveness was attributed to temperature, SD and TA. The parameter influencing the distinction in sampling site B was mainly $\mathrm{pH}$ while Mb site was influenced by DO, TN and TP in the dry season (Tamire and Mengistu, 2012).

The bio-plot of PCs associated with nutrients $\left(\mathrm{NH}_{3}-\mathrm{N}, \mathrm{NO}_{3}-\mathrm{N}, \mathrm{NO}_{2}-\mathrm{N}, \mathrm{SiO}_{2}-\mathrm{Si}, \mathrm{TIN}, \mathrm{PO}_{4}-\mathrm{P}\right.$ and TP), which were the key parameters characterizing the $\mathrm{Mb}$ and $\mathrm{Kb}$ sampling sites (Figure 4), can suggest an influence of agricultural activities in the catchment of the two rivers feeding the lake (Meki and Ketar Rivers) and Fa distinctiveness was attributed to temperature, TDS, EC and DO. The parameter influencing the distinction in the $\mathrm{K}_{\mathrm{o}}$ site was mainly $\mathrm{pH}$ while $\mathrm{Fb}$ site was influenced by DO, TN, TA and SD in the wet season.

The results from temporal PCA/FA suggested that agrochemicals pollution were potential pollution sources for both temporal clusters but that the influence of each was different. The results of the present study showed the existence of the contamination of Lake Ziway in both inorganic and organic agrochemicals mainly in the lake catchment in particular to $\mathrm{Fb}, \mathrm{Fa}, \mathrm{Mb}$ and $\mathrm{Kb}$ sampling sites. The major pollutant sources to the lake might be mainly from agricultural activities, human interference for different purposes, domestic wastes, industrial effluents and urban origin (Meshesha et al., 2012).

\section{Cluster analysis (CA)}

The three groups obtained by cluster analysis vary according to natural backgrounds features, land use and land cover, industrial structure and anthropogenic sources of pollution (Meshesha et al., 2012). The cluster analysis revealed different properties at each site with respect to physical and chemical variables.

Sites mainly located at middle reach of the lake (Station $C, M_{a}, K_{a}, K_{o}$ and $F_{a}$ ) were grouped under Cluster III, which were basically at the center of the lake and shore water. In addition, Station Ma and Ka located upstream of the lake, showed the similar water environment quality characteristics with these stations. Urbanization and industrialization level is relatively low at these sites. Direct discharged domestic wastewater contaminated the water; the cluster III correspond to relatively less polluted (LP), because the inclusion of the sampling location suggests the anthropogenic sources of pollution is less in the study period.

$\mathrm{Mb}$ and $\mathrm{Kb}$ sampling sites were grouped under cluster Il; the two stations are the tributaries of the lake; one is Meki River that drains part of the western high land and the second is the Ketar River which can drains the Arsi Mountains to the eastern part of the lake. These two rivers transported many agrochemicals from western high land and Arsi Mountains (Meshesha et al., 2012; Desta et al., 2016). Therefore, these sampling stations received pollutants mostly from agricultural runoff, domestic waste and industrial effluent from the local people and Meki and Abura towns (Meshesha et al., 2012; Desta et al., 2016). Cluster II corresponds to moderately pollution.

Sampling site Fb is grouped under Cluster $\mathrm{I}$; this cluster site is the effluents of the floriculture industries which is directly enter to the lake and polluted the lake water. Cluster I correspond to relatively highly polluted (HP) site, because the inclusion of floriculture 
industry, due to the untreated sewage of floriculture effluent at this site (Tadele, 2012). Accordingly, spatial variations of water quality in Lake Ziway showed that water quality was better in center and some portions of the shore water than in western and eastern areas in the lake. At the same time these results showed that for a rapid assessment of water quality, only one site in each cluster presents a useful spatial assessment of the water quality for the entire network in different seasons. This implies that, the results indicate the $\mathrm{CA}$ technique is useful in offering reliable classification of surface water in the whole region and make it possible to design a future spatial sampling strategy in an optimal method, which can reduce the number of sampling sites and associated costs. Similar reports have been dispatched by different authors (Sayadi et al., 2014; Badillo-Camacho et al., 20).

This implies that, for a rapid assessment of water quality, only one site in each cluster presents a useful spatial assessment of the water quality for the entire network in different seasons. In this study we found the PCA and CA analysis techniques are useful in apportionment of pollution sources based on parameter association. Similar findings has been reported in the study of Kazi, et al., (2009), Magyar et al. (2013), Mohammad et al. (2011), Sridhar et al. (2015).

\section{Comprehensive evaluation of Lake Ziway water quality analysis}

According to the comprehensive pollution index values sites $\mathrm{Fb}, \mathrm{Fa}, \mathrm{B}$ and $\mathrm{Mb}$ showed moderate pollution in dry season. The low water qualities parameters in these sites might be the influences of floriculture industry and domestic wastes from Ziway and Meki Towns. However, the wet season, the values of the comprehensive pollution index ranged from ( 0.38 to 0.68 ) demonstrated slight pollution of the whole sampling sites. The water quality of the lake was determined to have been influenced by different major source of pollution such as agricultural activities, domestic wastes, fishing industries, swimming and car washing.

\section{Conclusion}

The concentrations of most physicochemical parameters and nutrients showed high values in dry season and then decreased in wet season. All the nutrient species analyzed in the surface water of the lake showed increased trend and these variables might be primarily due to different environmental factors associated with intensive anthropogenic activities in the lake catchment specially, in western and eastern zones of the lake. The increasing trend in nutrient levels and in some water quality parameters in this study may lead to long term ecological changes in the lake ecosystem unless possible measures should be taken.

\section{Declarations}

Ethics approval and consent to participate:-“Not Applicable (NA)”

Consent for publication: - "Not Applicable (NA)"

Availability of data and materials:-The datasets used and/or analyzed during the current study are available from the corresponding author.

Competing interests:- The authors declare that they have no competing interests.

Funding: - Funding is not applicable for this study.

Authors' contributions:- DT and YT collected the samples and conducted the analysis. DT and BL designed the research and finalized the manuscript. FZ \& BL edited the manuscript. All authors read and approved the final manuscript.

Acknowledgment: - The authors gratefully acknowledge the support of Gondar University College of Natural and Computational Sciences and Addis Ababa University, College of Natural Science Water Thematic Research group for support the work.

\section{References}

1. Alemayehu W. 2010. Pesticide Risk Reduction Programme, 1-15.

2. Andrea M, Domagoj R. 2015. Evaluation of river water quality variations using multivariate statistical techniques. environmental monitoring and assessment,1:187-215

Page 17/24 
3. APHA (American Public Health Association).1999. Standard methods for the examination of water and wastewater, 20th ed., Washington D.C

4. APHRD (Animal and Plant Health Regulatory Directorate). 2010. List of registered pesticides as of May 2010. Animal and Plant Health Regulatory

5. Astel A, Tsakovski S, Simeonov V, Reisenhofer E, Piselli S, Barbieri P. 2008. Multivariate classification and Modeling in surface water pollution estimation. Anal Bioanal Chem, 390:1283-1292

6. Ayenew T. 2005. Major ions composition of the groundwater and surface water systems and their geological and geochemical controls in the Ethiopian volcanic terrain. SINET: Ethiopian Journal of Science, 28:171-188

7. Ayenew T, Legesse D. 2007. The changing face of the Ethiopian rift lakes and their environs; call of the time, Lakes and reservoirs: Research and management, 12: 149 -160

8. Ayenew T, Robert B. 2008. Comparative assessment of the water balance and hydrology of selected Ethiopian and Kenyan Rift Lakes, Lakes and Reservoirs: Research and Management., 13: 181-196

9. Badillo-Camacho J, Reynaga E, Barcelo-Quintal E, Orozco-Guareño C, Alvarez-Bobadilla D, Gomez-Salazar S. 2015. Water Quality Assessment of a Tropical Mexican Lake Using Multivariate StatisticalTechniques. Journal of environmental Protection, 6: 215-224

10. Beneberu G, Mengistou S. 2009. Oligotrophication Trend of Lake Ziway. SINET: Ethiopian Journal of Science, 32: 141-148.

11. Bharti N, Katyal D. 2011. Water Quality Indices Used for Surface Water Vulnerability Assessment. International Journal of environmental Science, 2:1-20

12. Dagne A. 2010. Zooplankton community structure, population dynamics and production in relation to abiotic and biotic factors in Lake Ziway, Ethiopia. PhD Theiss, University of Vienna, Wien, Austria.

13. Dagne A, Alois H, Christian J,Tadesse Z. 2008. Abundance, Species Composition and Spatial Distribution of Planktonic Rotifers and Crustaceans in Lake Ziway (Rift Valley, Ethiopia). International Review Hydrobiology, 93:210-226.

14. Desta H, Lemma B, Albert G, Stellmacher T. 2016. Degradation of Lake Ziway, Ethiopia: A study of the environmental perceptions of school students Lakes and Reservoirs: Research and Management, 20: 243-255

15. Dolotov A, Gapeeva M, Kozlovskii E. 2010. Assessment of the Uvod reservoir pollution with heavy metals. Journal of water Resource, 37:58-64

16. EU (Council of the European Union). 1998. on the Quality of Water Intended For Human Consumption, Council Directive 98/83/EC, OJ, 230: 1-10

17. Fetahi T. 2010. Plankton Communities and Ecology of Tropical Lakes Hayq and Awasa, Ethiopia, PhD Thesis, Vienna University, Austria

18. Gebre-Mariam Z. 2002. The effects of wet and dry seasons on concentrations of solutes and phytoplankton biomass in seven Ethiopian rift-valley lakes. Limnologica, 32:169-179

19. Ghafar A, Muhammad A, Murtaza G, Faryal K, Hussain K, Ameen Q, Nasrullah M. 2014.Comparative study of water quality of Manchar Lake with drinking water quality standard of world health organization, American Journal Environmental Protection, 3: $68-72$

20. Jansen H, Harmsen J. 2011. Pesticide Monitoring in the Central Rift Valley 2009-2010. Ecosystems for Water in Ethiopia. Wageningen, Alterra, Alterra-rapport 2083.

21. Jansen H, Hengsidijk H, Legesse D, Ayenew T, Hellegers P, Speliethoff P. 2007. Land and water resources assessment in the Ethiopian Central Rift Valley; Project: ecosystems for water, food and economic development in the Ethiopian Central Rift Valley. Wageningen, Alterra, Alterra report 1587.

22. Kazi T, Arain M, Jamali M, Afridi H, Sarfraz R, Baig J, Shah A. 2009. Assessment of Water Quality of Polluted Lake Using Multivariate Statistical Techniques: A Case Study. Ecotoxicology Environment Safety, 72: 301-309.

23. Kebede M, Sheleme Beyene. 2012. Modeling the influence of floriculture effluent on soil quality and dry matter yield of wheat on Fluvisols at Ziway. Journal of environmental and Earth Science, 2:1-16

24. Legesse D, Valett C, Gasse F. 2001. Precipitation-runoff modeling in the Ziway-Shala Basin, Ethiopian Rift Valley. Journal of Hydrology, 245:1-18. 
25. Leo M, Nollet L, Lee S, Gelder L. 2014. Hand Book of Water Analysis, 3rd edit., CRC Press Taylor and Francis Group, Germany.

26. Liu C, Lin K, Kuo Y. 2003. Application of factor analysis in the assessment of groundwater quality in a black foot disease area in Taiwan. The Science of Total Environment, 313: 77-89.

27. Magyar N, Hatvani I, Székely I, Herzig A, Dinka M, Kovács J. 2013. Application of multivariate statistical methods in determining spatial changes in water quality in the Austrian part of Neusiedler See. Ecology of Engineeing, 55: 82-92.

28. Meshesha T, Tsunekawa A, Tsubo M. 2012. Continuing land degradation: cause-effect in Ethiopia's central Rift Valley land Degradation and Development, 23: 130 -143

29. Mohammad A, Bhuiyan M, Rakib A, Dampare B, Ganyaglo S. 2011. Surface Water Quality Assessment in the Central Part of Bangladesh Using Multivariate Analysis. J. Civ. Engin. 15: 995-1003

30. Population and Housing Census of Ethiopia. 2007. Results for Oromia Region, 1: 349

31. Population and Housing Census of Ethiopia. 1994. Results for Oromia Region, 1:114

32. Roba B. 2008. Physicochemical and Bacteriological Water Quality Assessment in Lake Ziway with a Special Emphasis on Fish Farming, MSc Thesis, Addis Ababa University, Ethiopia

33. Rubio-Arias H, Ochoa-Rivero J, Quintana R, Saucedo-Teran R, Ortiz-Delgado C, Rey-Burciaga L, Espinoza-Prieto R. 2013. Development of a Water Quality Index of an Artificial Aquatic Ecosystem in Mexico. Journalf Environtal Protection, 4:12961306

34. Sayadi M, Rezae A, Rezaei M, Nourozi K. 2014. Multivariate statistical analysis of surface water chemistry: A case study of Gharasoo River, Process of International Academic of Ecological Environmental Science, 4: 114-122

35. Shrestha S, Kazama F. 2007. Assessment of surface water quality using multivariate statistical techniques: A case study of the Fuji river basin, Japan Environmental Model Software, 22: 464-475

36. Simeonov V, Simeonova P, Tsakovski S, Lovchinov V. 2010. Lake water monitoring data assessment by multivariate statistics. Journal of water Resource Protection, 2: 353-361.

37. Singh K, Malik D, Mohan Sinha S. 2004. Multivariate statistical techniques for the evaluation of spatial and temporal variations in water quality of Gomti River: a case study, Water Resource, 38: 3980-3992.

38. Sridhar K, Madhava R, Srinivas L, Manikya R. 2015. Assessment of Surface Water Quality in Hyderabad Lakes by Using Multivariate Statistical Techniques. Environmental Pollution, 4: 1-10

39. Tadele M. 2012. Environmental Impacts of Floriculture Industries on Lake Ziway: Pollution Profiles of Lake Ziway along Floriculture Industries, LAP LAMBERT Academic Publishing, Germany

40. Talling F, Lemoalle J.1998. Ecological dynamics of tropical inland waters. Cambridge University Press, UK.

41. Tamire G, Mengistou M. 2012. Macrophytes species composition, distribution and diversity in relation to some physicochemical factors in the littoral zone of Lake Ziway. African Journal Ecology, 51: 66-77.

42. Tamire G, Mengistu S. 2014. Biomass and net aboveground primary productivity of macrophytes in relation to physicochemical factors in the littoral zone of Lake Ziway. Tropical Ecology, 55: 313-326.

43. Tilahun G, Gunnel A. 2010. Seasonal variations in phytoplankton biomass and primary production in the Ethiopian Rift Valley lakes Ziway, Awasa and Chamo The basis for fish production. Limnologica, 40: 330-342

44. Tilahun G. 2006. Temporal dynamics of the species composition, abundance and size-fractionated biomass and primary production of phytoplankton in Lakes Ziway, Awasa and Chamo. Ph.D. Thesis, Addis Ababa University, Ethiopia.

45. Tilahun G.1988. A seasonal study on primary production in relation to light and nutrients in Lake Ziway, M.Sc Thesis, Addis Ababa University, Ethiopia

46. Turdu C, Bernard G, Elisabeth G.1999. The Ziway-Shala lake basin system, Main Ethiopian Rift: Influence of volcanism, tectonics, and climatic forcing on basin formation and sedimentation, Palaeogeography, Palaeoclimatology. Palaeoecology, 150: $135-177$

47. Varol M, Sen B. 2009. Assessment of surface water quality using multivariate statistical techniques: a case study of Behrimaz Stream. Environmental Monitoring and Assessment, 159:543-553 
48. Vessely J, Majer V, Koacek J, Safanda J, Norton S. 2005. Increasing silicon concentrations in Bohemian Forest Lakes, Hydro \& Earth system science, 9: 699-706

49. WHO (World Health Organization).1996. Guidelines for Drinking-water Quality: Health Criteria and Other Supporting Information. 2nd ed.

50. Yang J, Skogley E, Schaff B, Kim J.1998. A simple spectrophotometric determination of nitrate in water. Soil Science and Social American Journal, 62:1108-1115.

51. Yan A, Zhang W, Zhang Z, Liu Y, Deng C, Nie N. 2015. Assessment of Water Quality and Identification of Polluted Risky Regions Based on Field Observations \& GIS in the Honghe River Watershed, china, 10:1-13

52. Yohannes F. 2003. Management of Lake Ziway Fisheries in Ethiopia, Msc Thesis, University Of Tromsø, Norway.

53. Zeray L, Roehrig J, Alamerew D. 2007. Climate Change Impact on Lake Ziway Watershed Water Availability, Ethiopia. 1: 1-6.

54. Zhao J, Fu G, Lei K, Li Y. 2011. Multivariate analysis of surface water quality in the Three Gorges area of China and implications for water management. Journal of environmental Science, 23: 1460-1471

\section{Figures}

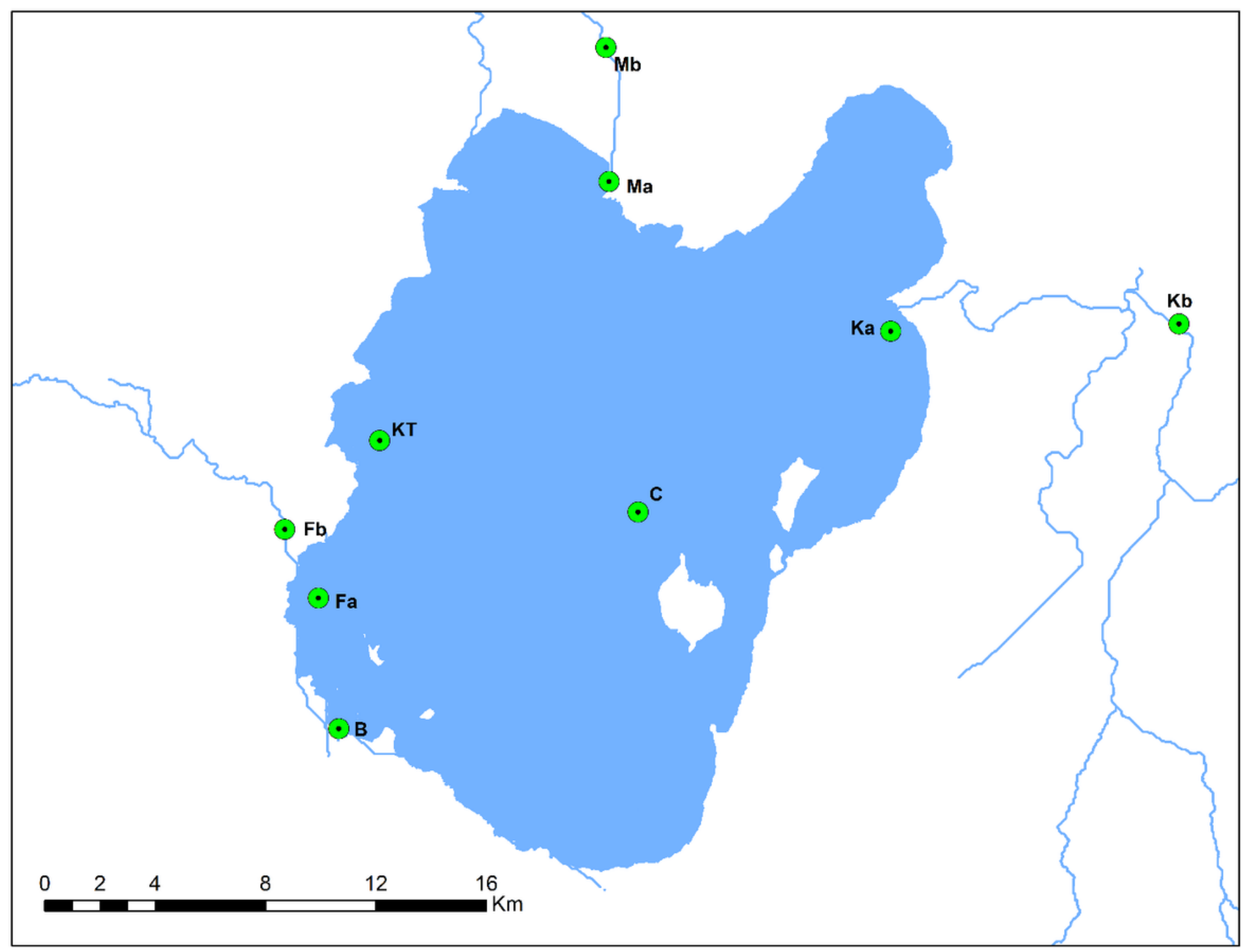

Figure 1 
Location and bathymetric Map of Lake Ziway and its tributaries in Ethiopia (Turdu et al., 1999) with the sampling sites designated as shown in Table 1, below.
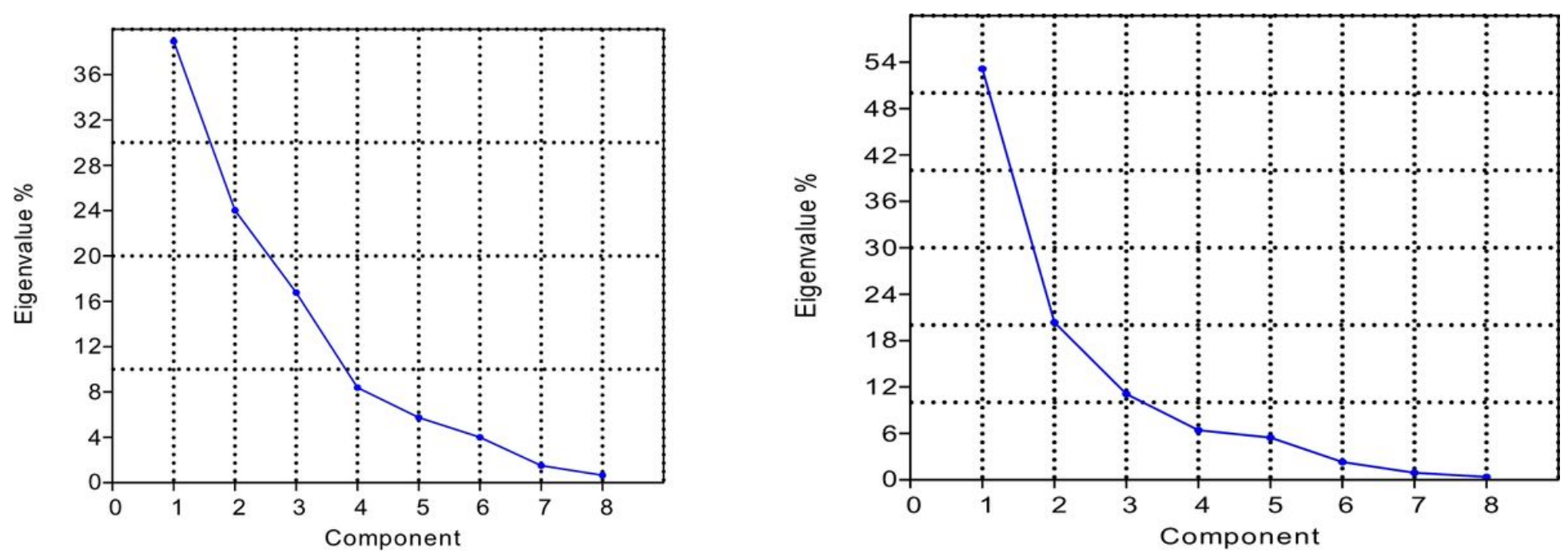

Figure 2

a wet season Scree plot of the eigenvalues. Figure

b dry season Scree plot of the eigenvalues

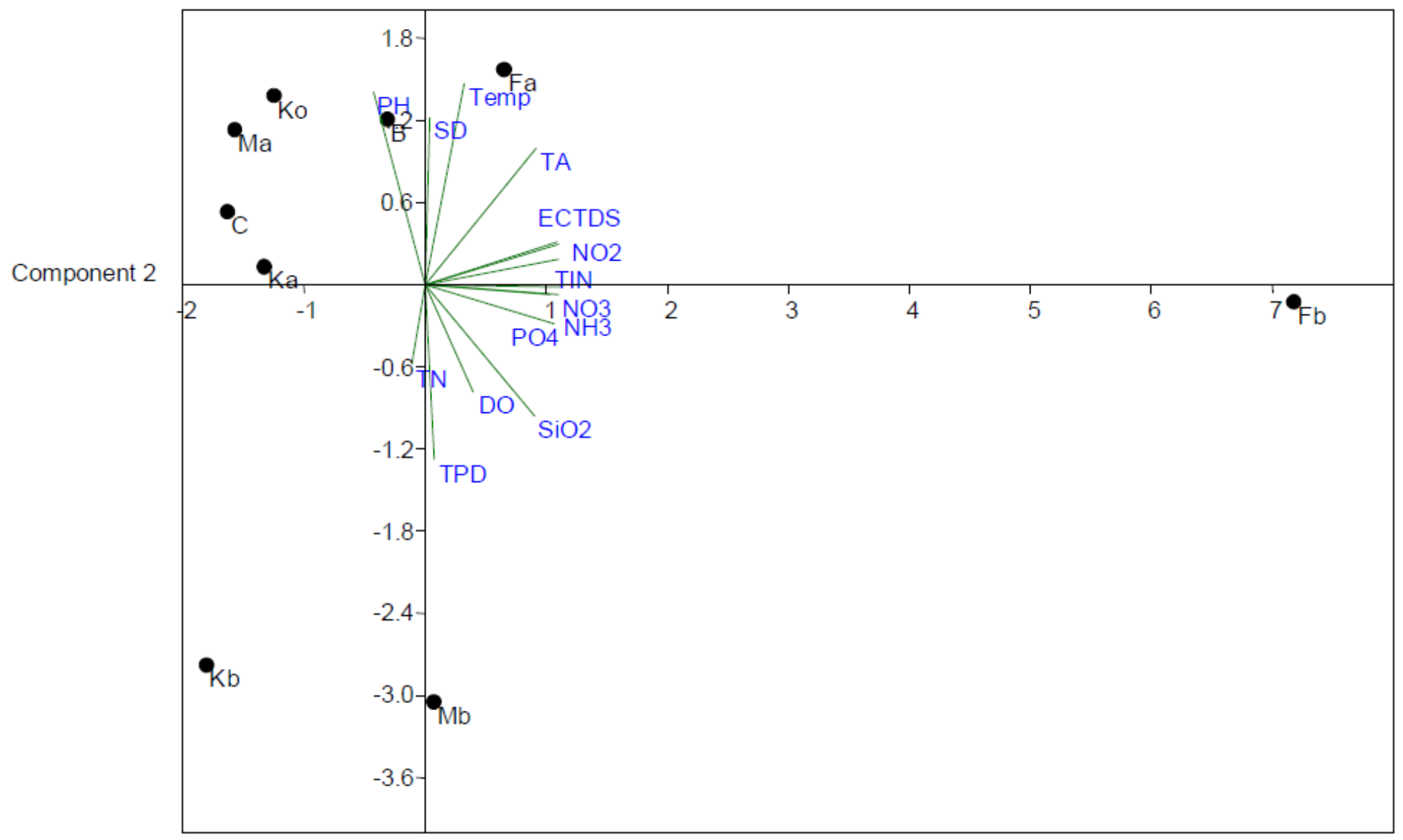

Component 1

Figure 3 
Results of the bi-plot of the correlation between for various water quality parameters with respect to studied sites using PCA in the dry season

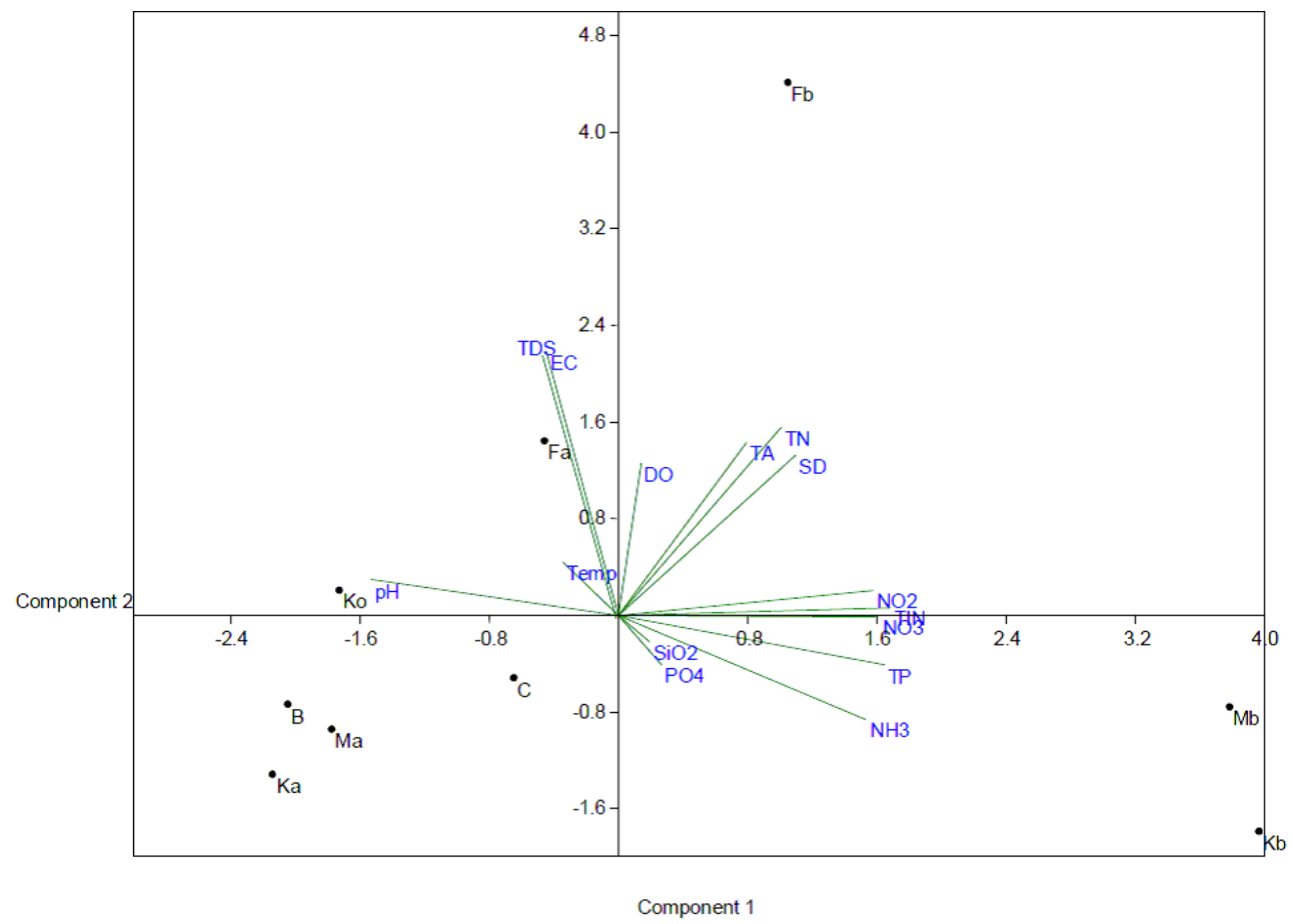

\section{Figure 4}

Results of the bi-plot of the correlation between for various water quality parameters with respect to studied sites using PCA in the wet season 


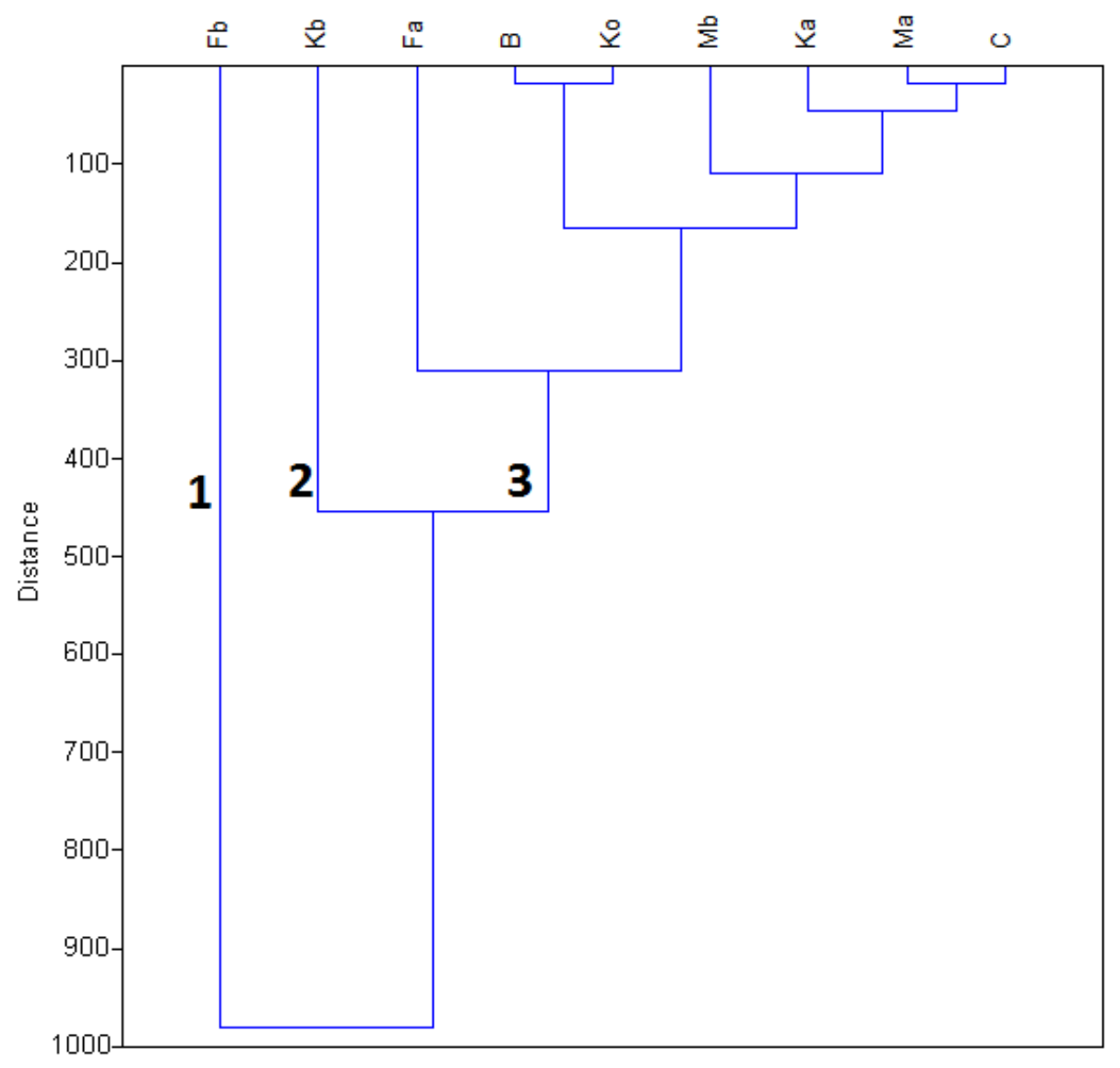

\section{Figure 5}

Dendrogram based for agglomerative hierarchical clustering (wards method) based on the PCA scores in dry season 


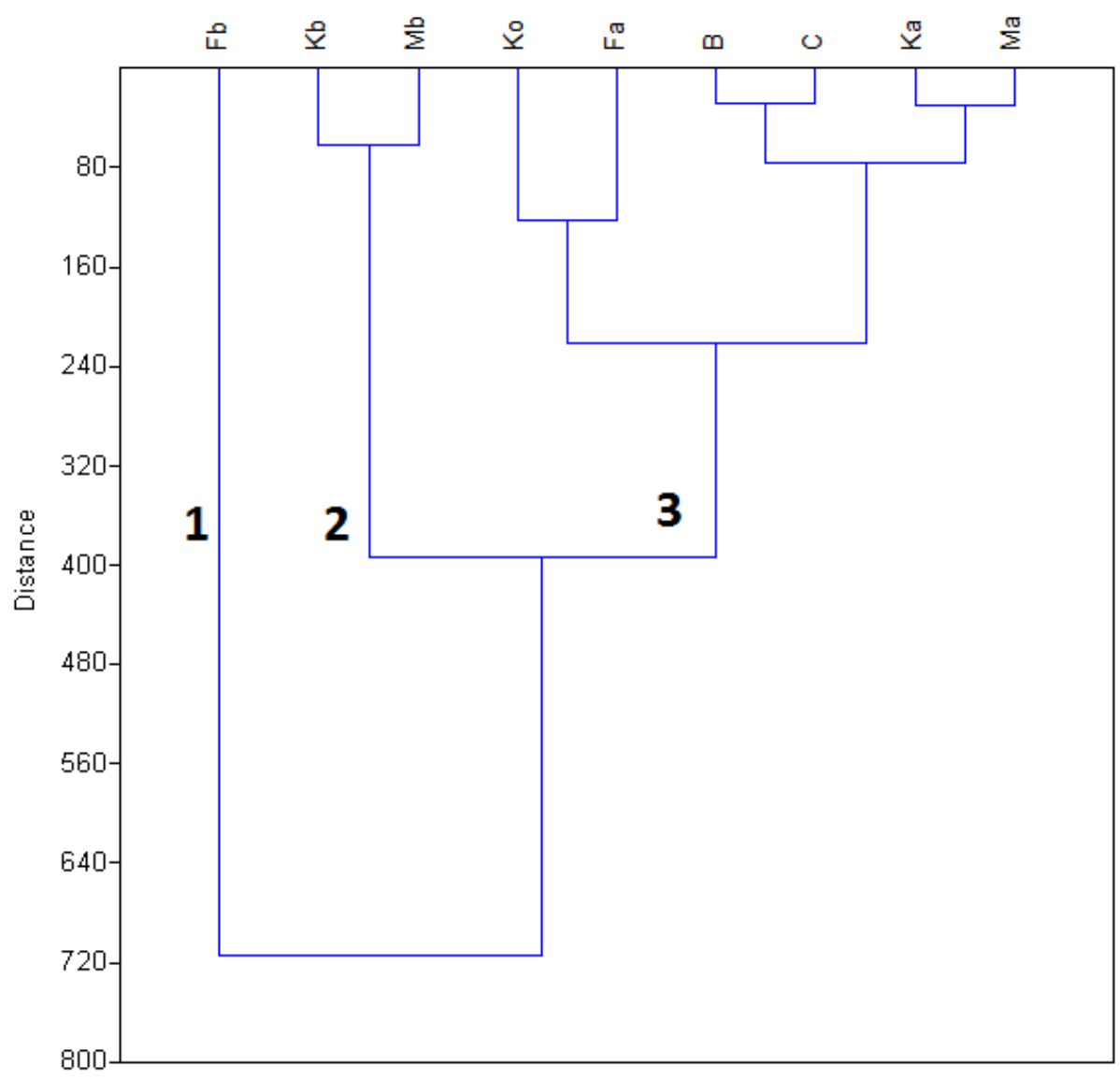

\section{Figure 6}

Dendrogram based for agglomerative hierarchical clustering (wards method) based on the PCA scores in the wet season 